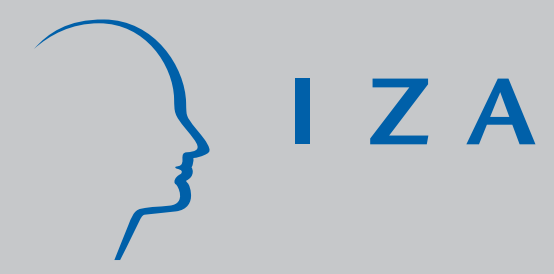

IZADP No. 2222

Product Market Regulation and Endogenous Union Formation

Monique Ebell

Christian Haefke

July 2006 


\title{
Product Market Regulation and Endogenous Union Formation
}

\author{
Monique Ebell \\ Humboldt University of Berlin \\ Christian Haefke \\ Institute for Advanced Studies, Vienna, \\ Instituto de Análisis Económico, CSIC \\ and IZA Bonn
}

Discussion Paper No. 2222

July 2006

\author{
IZA \\ P.O. Box 7240 \\ 53072 Bonn \\ Germany \\ Phone: +49-228-3894-0 \\ Fax: +49-228-3894-180 \\ Email: iza@iza.org
}

\begin{abstract}
Any opinions expressed here are those of the author(s) and not those of the institute. Research disseminated by IZA may include views on policy, but the institute itself takes no institutional policy positions.

The Institute for the Study of Labor (IZA) in Bonn is a local and virtual international research center and a place of communication between science, politics and business. IZA is an independent nonprofit company supported by Deutsche Post World Net. The center is associated with the University of Bonn and offers a stimulating research environment through its research networks, research support, and visitors and doctoral programs. IZA engages in (i) original and internationally competitive research in all fields of labor economics, (ii) development of policy concepts, and (iii) dissemination of research results and concepts to the interested public.
\end{abstract}

IZA Discussion Papers often represent preliminary work and are circulated to encourage discussion. Citation of such a paper should account for its provisional character. A revised version may be available directly from the author. 


\title{
ABSTRACT \\ Product Market Regulation and Endogenous Union Formation*
}

\begin{abstract}
We contribute to the growing literature which aims to link product market regulation and competition to labor market outcomes, in an attempt to explain the divergent US and continental European labor market performance over the past two decades. The main contributions of this paper are threefold. First, we show that the choice of bargaining regime is crucial for the effect of product market competition on unemployment rates, being substantial under collective bargaining and considerably more modest under individual bargaining. Since the choice of bargaining institution is so important, we endogenize it. We find that the bargaining regime which emerges endogenously depends crucially on the degree of product market competition. When product market competition is low, collective bargaining is stable, while individual bargaining emerges as the stable institution under high degrees of product market competition. This also allows us to link product market competition and collective bargaining coverage rates. Our results suggest that the strong decline in collective bargaining coverage and unionization in the US and UK over the last two decades might have been a direct consequence of the Reagan/Thatcher product market reforms of the early 80's. Finally, we calibrate the model to assess the quantitative magnitude of our results. We find that moving from the US low regulation-individual bargaining economy to the EU high regulation-collective bargaining economy leads to a substantial increase in equilibrium unemployment rates from $5.5 \%$ to $8.9 \%$ in the model economy.
\end{abstract}

JEL Classification: E24, J63, L16

Keywords: product market competition, European Unemployment Puzzle, overhiring, wage bargaining

Corresponding author:

Christian Haefke

Instituto de Análisis Economico, CSIC

Campus UAB

E-08193 Bellaterra

Barcelona

Spain

E-mail: christian.haefke@upf.edu

\footnotetext{
* We thank Michael Burda, Ken Burdett, Jordi Galí, Harald Uhlig, Randy Wright, and Fabrizio Zilibotti for helpful comments. All remaining errors are of course our own.
} 


\section{Introduction}

A growing literature examines the consequences of product market regulation and competition for labor market outcomes. Indeed, product market regulation is one of the most striking ways in which the US and continental European economies differ. To give an idea of the magnitudes involved, Table 1 presents an index of barriers to entry in the US and in the European Union, compiled by Fonseca, Lopez and Pissarides (2001) and based on OECD data. The index combines the average time required to establish a standardized firm with the number of procedures necessary into a weeks-based measure of entry delay. The measured delays range from 8.6 business days in the United States to a whopping 85 days in Spain. The population-weighted EU average of 54.7 days is many times larger than the corresponding American figure. Djankov, et.al. (2002) report data on a second dimension of entry barriers, namely the pecuniary cost of establishing a standardized firm as a percentage of the per capita GDP of the respective country. This data is also reproduced in Table 1. Once again, the gulf between the Anglo-American world and Europe is striking: establishing a firm in the US costs less than $1 \%$ of per capita GDP, while establishing the average continental European firm costs $18.4 \%$ of per capita GDP. The European barriers to entry are an order of magnitude larger. It seems reasonable that such large differences in entry barriers might translate into large differences in labor market outcomes.

There is a growing body of empirical evidence to support the link between product market regulation and labor markets. Schiantarelli (2005) summarizes the recent empirical literature and finds clear evidence that product market regulation that raises barriers to entry contributes to higher mark-ups. Bertrand and Kramarz (2002) examine the impact of French legislation, the Loi Royer of 1974, which regulated entry into French retailing. They find that those regions (departements) which restricted entry more strongly, experienced slower rates of job growth. Boeri, Nicoletti and Scarpetta (2000), using an OECD index of the degree of product market regulation, also report a negative relationship between their regulation measure

and employment. Fonseca, et. al. (2001) show that their index of entry barriers is negatively correlated with employment and positively correlated with unem- 
ployment rates. Moreover, the timing of US and UK product market deregulation efforts, which began in the late 1970's, fits neatly into the picture of labor market performance which began to diverge in the early 80's, as illustrated in Figure 1. Hence, product market deregulation is a sort of smoking gun for divergent US and European labor market performance, whose implications are worth investigating.

Relatively little previous theoretical work has analyzed whether and how product market rigidities may affect equilibrium labor market outcomes. Nickell (1999) provides an insightful overview of early work which is either partial equilibrium or employing some form of collective bargaining exclusively. Recent important contributions are the papers of Fonseca, Lopez and Pissarides (2001) and Blanchard and Giavazzi (2003). Fonseca, et. al. (2001) focuses on the impact of entry barriers on the decision to become an entrepreneur or a worker, finding that entry barriers can indeed lead to lower rates of entrepreneurship and hence job creation, and ultimately to higher rates of equilibrium unemployment. However, in Fonseca et. al. (2001)'s model, firms face barriers to entry but perfect competition. In contrast, Blanchard and Giavazzi (2003) study labor market outcomes in a model with monopolistic competition but with a more stylized labor-market setting. They find that equilibrium unemployment is decreasing in the degree of product market competition, and also emphasize that equilibrium wages are increasing in the degree of product market competition. In a similar vein, Spector (2004) studies the effects of changes in the intensity of product market competition in a model with capital and concludes that product-market and labor-market regulations tend to reinforce each other. The latter two papers consider static or two-period setups. Ebell and Haefke (2006) present a fully dynamic model which combines monopolistic competition in goods markets and Mortensen-Pissarides-style search frictions with multi-worker firms and individual bargaining. In this earlier contribution, we show that the impact of product market reform on unemployment rates is surprisingly small under individual bargaining. Our work is also related to important earlier work on individual bargaining by Smith (1999) and Cahuc, Marque and Wasmer (2004).

The current paper makes three main contributions. First, we show that the choice of bargaining institution is crucial for the impact of product market reform on unemployment. The impact of product market reform is negligible for indi- 
vidual bargaining, and substantial (more than 3 percentage points) for collective bargaining. The reason is that under collective bargaining, only the first principles effect of expanded output and hiring due to increasing competition is at work. Under individual bargaining, however, there is an additional countervailing overhiring effect. The overhiring effect is explained in detail in Ebell and Haefke $(2006)^{1}$. Firms wish to hire workers beyond the employment level at which marginal revenue product covers employment costs. Firms do this because hiring an additional worker depresses the wages of all individual-bargaining workers, if marginal revenue product is decreasing. Since marginal revenue product is more steeply decreasing the lower is competition, the amount of overhiring is increasing in monopoly power. Hence, when monopoly power is high, individual bargaining firms optimize by both restricting output and employment to keep prices high by first principles, but also by expanding output and employment due to the overhiring effect. The overhiring effect counteracts the first principles effect nearly fully, and the total effect is that employment and unemployment are nearly flat in the degree of product market competition under individual bargaining.

Since the choice of bargaining regime is crucial, we proceed to endogenize it. Hence, our second main contribution is to show how workers' endogenous choice of bargaining regime changes with the degree of product market competition. In particular, collective bargaining turns out to be the unique symmetric Nash equilibrium in the high-entry cost regime, while individual bargaining is an equilibrium in the low-entry cost regime. The intuition for this result is straightforward: collective bargaining gives workers a profit share as their bargaining surplus. Hence, the surplus which can be gained by collective bargaining is decreasing in product market competition. In contrast, the individual bargaining surplus depends on the marginal value of each worker, which in equilibrium are equalized to the costs to hiring the marginal worker. Hiring costs are increasing in product market competition, since competition induces all firms to open more vacancies, making it more costly to find a new worker. Hence, collective bargaining surplus is decreasing in competition, while individual bargaining surplus is increasing in competition. This

\footnotetext{
${ }^{1}$ Overhiring effects in individual bargaining were first noted in a partial equilibrium setting by Stole and Zwiebel (1996a, 1996). In general equilibrium, Smith (1999) shows that overhiring can be important when firms' technology is characterized by decreasing returns to scale.
} 
leads workers to prefer collective bargaining when monopoly power is high, but also to prefer individual bargaining when monopoly power is low enough.

Taken together, we see that when the choice to bargain collectively is endogenized, then going from high to low entry costs - and hence from high to low monopoly power - does indeed have a substantial effect on unemployment. To quantify the effects of product market reform on equilibrium unemployment rates, we calibrate the model and run a simple policy experiment. The policy experiment consists of beginning with a calibration of the relevant low US entry cost [high competition] and individual bargaining setup to US data. Then, we increase the entry costs to their significantly higher continental European levels. Under continental European entry costs, collective bargaining turns out to be the appropriate bargaining institution, which can be supported as a symmetric Nash equilibrium. The resulting increase in unemployment rates when moving from the high competitionindividual bargaining US case to the low competition-collective bargaining European case is indeed a substantial $3.4 \%$ points of unemployment. In particular, unemployment increases from $5.5 \%$ to $8.9 \%$ in the model economy, accounting for about $85 \%$ of the four percentage point difference between average US and European unemployment rates in the 90's. Hence, product market regulation may be a key factor in explaining the relatively poor performance of continental European labor markets.

Our final contribution is to the literature which aims to explain the decline of union density and collective bargaining coverage rates ${ }^{2}$. Our findings suggest that the dramatic declines in both measures of union activity in the US and UK in the 80 's and 90's was spurred by the product market deregulation efforts of the Reagan administration and the Thatcher government. Figure 2 shows that the share of private sector workers in the US who are covered by a collective bargaining agreement has decreased from $23.3 \%$ in 1977 (the first year that data was collected) to less than 10\% after 2000. Moreover, Figure 3 reveals a clear positive relationship between competition and union coverage for a cross section of U.S. industries. Importantly,

\footnotetext{
${ }^{2}$ The union density is the fraction of employed workers who are union members. The collective bargaining coverage rate gives the percentage of workers covered by a collective bargaining agreement, regardless of whether they are union members or not.
} 
the deunionization in our model is voluntary: workers choose to abstain from forming collective bargaining coalitions, because they prefer the higher wages they can obtain by bargaining individually with their employers. The relatively gradual decline in unionization rates is also supported by the transition dynamics of our model. At sufficiently high degrees of product market competition, both collective and individual bargaining are stable arrangements, and can coexist. Since firms always earn higher profits under individual bargaining, they will choose it as their initial bargaining arrangement and will hire an according number of steady state workers. When competition is high enough so that individual bargaining is stable, workers will also choose to retain it rather than switching to collective bargaining. Collective bargaining does, however, remain a stable institution at all levels of competition. Hence, after a product market deregulation, existing collective bargaining coalitions (unions) are stable, but new firms, who begin life without a union, never acquire one. This is consistent with Machin (2000)'s findings that British deunionization was largely a result of the failure of new establishments to organize, rather than the breakdown of unions in existing workplaces.

The remainder of the paper is organized as follows: Section 2 presents the basic model, and section 3 goes on to describe both the individual and the collective bargaining setups. Section 4 is concerned with general equilibrium for both bargaining regimes. Section 5 calibrates the model to U.S. data, and compares the impact of a product market deregulation on unemployment under collective and individual bargaining. The choice of bargaining regime is endogenized in Section 6, and is shown to depend upon the degree of competition. Section 7 presents the calibrated model and the policy experiment, which quantifies the impact of a product market deregulation on unemployment, taking into account that the deregulation may also lead to a shift in the endogenously chosen bargaining regimes. Section 8 examines the transition dynamics due to a product market deregulation, while section 9 concludes. 


\section{The Basic Model}

In this section we present the basic model. Its main elements are monopolistic competition in the goods market and Mortensen-Pissarides-style matching with multi-worker firms in the labor market. We restrict our analysis to the steady state.

\subsection{Households}

\subsubsection{Search and Matching in the Labor Market}

The labor market is characterized by a standard search and matching framework. Unemployed workers $u$ and vacancies $v$ are converted into matches by a constant returns to scale matching function $m(u, v)=s \cdot u^{\eta} v^{1-\eta}$. Defining labor market tightness as $\theta \equiv \frac{v}{u}$, the firm meets unemployed workers at rate $q(\theta)=s \theta^{-\eta}$, while the unemployed workers meet vacancies at rate $\theta q(\theta)=s \theta^{1-\eta}$.

In the basic model, workers are identical. Workers may be employed at firms with either of two wage bargaining institutions: individual or collective. We index the firm's wage-bargaining institution by $k \in\{I, C\}$. In addition, the aggregate bargaining environment - the bargaining institutions chosen by all other firms is indexed by $\mu$, which gives the measure of firms choosing collective bargaining. When $\mu=1$, all other firms in the economy choose collective bargaining. When $\mu=0$, all other firms choose individual bargaining. The mix of bargaining institutions will turn out to influence labor market tightness, leading to the notation $\theta_{\mu}$. For each worker, the value of employment is given by $V_{k}^{E}\left(\theta_{\mu}\right)$, which satisfies ${ }^{3}$ :

$$
r V_{k}^{E}\left(\theta_{\mu}\right)=w_{k}\left(\theta_{\mu}\right)-\chi\left[V_{k}^{E}\left(\theta_{\mu}\right)-V^{U}\left(\theta_{\mu}\right)\right]
$$

where $\chi$ is the total separation rate. Firms and workers may separate either because the match is destroyed, which occurs with probability $\tilde{\chi}$ or because the firm has exited, which occurs with probability $\delta$. We assume that these two sources of separation are independent, so that the total separation probability is given by

\footnotetext{
${ }^{3}$ We assume that all payments are made at the end of a period so that our value functions in discrete time actually coincide with their continuous time counterpart. Equation (1) can be obtained from

$$
r V^{E}[k, \theta(\mu)]=\frac{1}{1+r}\left(w_{k}[\theta(\mu)]+(1-\chi) V^{E}[k, \theta(\mu)]+\chi V^{U}[\theta(\mu)]\right)
$$
}


$\chi=\widetilde{\chi}+\delta-\widetilde{\chi} \delta$. Explicit firm exit is incorporated mainly for quantitative reasons. If firms were counterfactually infinitely lived, then the impact of a given level of entry costs would be greatly understated, since firms could amortize those entry costs over an infinite lifespan.

The value of unemployment is standard and is the same for all workers. In particular, the value of unemployment depends exclusively upon the aggregate choice of bargaining institution $\mu$ :

$$
r V^{U}\left(\theta_{\mu}\right)=b P+\theta_{\mu} q\left(\theta_{\mu}\right)\left[\mu V_{C}^{E}\left(\theta_{\mu}\right)+(1-\mu) V_{I}^{E}\left(\theta_{\mu}\right)-V^{U}\left(\theta_{\mu}\right)\right]
$$

where $P$ denotes the aggregate price level and $b$ real unemployment benefits. The reason that $r V^{U}\left(\theta_{\mu}\right)$ depends solely on the aggregate mix of bargaining institutions $\mu$ is that each individual firm or industry will be assumed to be atomistic with respect to the economy at large. Hence, the probability of being rehired by one's own firm is zero, so that each worker's own firm's bargaining decisions are irrelevant for his reemployment prospects.

\subsubsection{Monopolistic Competition in the Goods Market}

Households are both consumers and workers. As consumers they are risk neutral in the aggregate consumption good. Agents have Dixit-Stiglitz preferences over a continuum of differentiated goods. Goods demand is derived from the household's optimization problem:

$$
\max \left(\int c_{i, n}^{\frac{\sigma-1}{\sigma}} d i\right)^{\frac{\sigma}{\sigma-1}}
$$

subject to the budget constraint $I_{n}=\int c_{i, n} \frac{P_{i}}{P} d i$ where $I_{n}$ denotes the real income of household $n$ and $c_{i, n}$ is household $n$ 's consumption of good $i$. In order to focus the dynamics on the labor market, there is no saving or capital. Thus we obtain aggregate demand for good $i$ given as:

$$
Y_{i}^{D} \equiv \int c_{i, n} d n=\left(\frac{P_{i}}{P}\right)^{-\sigma} I
$$

where $I \equiv \int I_{n} \mathrm{~d} n$ is aggregate real income and $P=\left(\int P_{i}^{1-\sigma}\right)^{\frac{1}{1-\sigma}}$ is the price index . Equation (4) is the standard monopolistic-competition demand function with elasticity of substitution among differentiated goods given by $-\sigma$. 


\subsection{Multiple-worker Firms}

Firms are monopolistically competitive. Each firm faces demand elasticity $-\sigma$, in line with the Dixit-Stiglitz assumptions above. Monopolistic competition makes it imperative to abandon the one-worker firm assumption. To see this, recall that assuming one-worker firms is harmless under perfect competition and constant returns to scale [cf. Cahuc and Wasmer (2001)], since the number and size of firms is indeterminate. Under monopolistic competition, however, firm size and hence output are determined optimally in equilibrium, as a function of the elasticity of demand. Continuing to assume one-worker firms would be tantamount to imposing a restriction on the model which is generically inconsistent with optimal firm behavior.

To see this point more clearly, recall that from first principles, firms' optimal reaction to an increase in monopoly power is to restrict output. The only way to vary output with a given technology is to vary the amount of labor employed either on the extensive margin or the intensive margin. ${ }^{4}$ Consistent with stylized facts, we assume that firms adjust employment by varying the number of workers [extensive margin] rather than the number of hours per worker.

We consider two wage bargaining settings, each of which gives rise to a different decision-making environment for the multi-worker firm. Under individual bargaining, the firm bargains separately with each worker. In this individual bargaining setting, it is natural that the firm can choose freely its profit-maximizing steady-state employment level. Under collective bargaining, the firm bargains with a coalition of all workers employed at its firm. In the collective bargaining setting, it is natural to make the total number of workers subject to negotiation as well (efficient bargaining), since the collectively bargaining workers do have the power to refuse to work at all if their hiring preferences are not respected. We index the firm-level bargaining institution by $k \in\{I, C\} .{ }^{5}$

\footnotetext{
${ }^{4}$ In a model with capital, firms could also vary output by varying only the amount of capital employed. In order to maintain an optimal capital-labor ratio, however, firms would also generally adjust by varying labor as well.

${ }^{5}$ We have also examined the right-to-manage case, in which workers bargain collectively over wages but firms retain the right to choose employment freely. The results remain the same. Details are available from the authors upon request.
} 
Nonetheless, both types of firms face the same optimization problem. Both maximize the discounted value of future profits, and in both cases the firm's state variable is the number of workers currently employed, $H_{i}$, where index $i$ represents the firm and $k$ denotes the firm's bargaining institution. Firms' key decision is the number of vacancies. Firms open as many vacancies $v_{i}^{k}$ as necessary to hire in expectation the desired number of workers next period, while taking into account that the real cost to opening a vacancy is $\Phi_{V}$. Each firm's problem becomes:

$$
V_{k}^{J}\left(H_{i}\right)=\max _{H_{i}^{\prime}, v_{i}} \frac{1}{1+r}\left\{P_{i}^{k}\left(Y_{i}\right) Y_{i}-w_{k}\left(H_{i}\right) H_{i}-\Phi_{V} P v_{i}+(1-\delta) V_{k}^{J}\left(H_{i}^{\prime}\right)\right\}
$$

subject to

$$
\begin{aligned}
\text { demand function: } & \frac{P_{i}^{k}\left(Y_{i}\right)}{P}=\left(\frac{Y_{i}}{I}\right)^{-\frac{1}{\sigma}} \\
\text { production function: } & Y_{i}=A H_{i} \\
\text { transition function: } & H_{i}^{\prime}=(1-\widetilde{\chi}) H_{i}+q\left(\theta_{\mu}\right) v_{i} \\
\text { wage curve: } & w_{k}\left(H_{i}\right)
\end{aligned}
$$

where the wage curve represents the outcome of the wage bargaining process. Since both types of firms face the same optimization problem, we obtain the same first order condition for both (analogous to the Job Creation Condition of the oneworker firm):

$$
\frac{1}{1-\delta} \frac{\Phi_{V} P}{q\left(\theta_{\mu}\right)}=\frac{\partial V_{k}^{J}\left(H_{i}^{\prime}\right)}{\partial H_{i}^{\prime}}
$$

By (10), the marginal value of an additional worker must equal the cost of searching for him/her, weighted by the probability of firm survival $1-\delta$.

Firm entry and exit works as follows: Each period, a measure $\delta$ of firms exits and is replaced by a measure $\delta$ of entrants. Entrants begin producing at the steadystate level immediately. This presumes that firms know in advance that they will enter. In the pre-entry phase, firms pay the entry cost and post enough vacancies $\left(v_{0}=\frac{H_{i}}{q(\theta)}\right)$ to hire their steady-state employment level ${ }^{6}$.

\section{Bargaining}

In this section we describe both the individual and the collective wage bargaining, and derive firm-level wage-employment equilibria, taking as given workers' choice

\footnotetext{
${ }^{6}$ This is completely natural because hiring costs are linear in the number of posted vacancies.
} 
of bargaining institution.

\subsection{Individual Bargaining}

The microfoundation for individual bargaining is provided by Stole and Zwiebel (1996), who show that individual bargaining may be understood as a BinmoreRubinstein-Wolinsky (1986) alternating offer game, ensuring that the Nash-bargaining is fully microfounded. Hence the individual-bargaining wage curve (15) can be obtained either by fully modeling the pairwise bargaining structure, or by solving a standard generalized Nash bargaining problem ${ }^{7}$. In this sense, individual bargaining is the natural extension of the Mortensen-Pissarides framework to multiworker firms, since it allows us to derive the wage curve by solving the Nash bargaining problem.

The key assumption of the Stole and Zwiebel (1996) individual bargaining framework used here is that firms engage in pairwise negotiations with workers. When a worker joins the firm, wages are renegotiated individually with all workers. The crucial point of the individual bargaining framework is that each worker is treated as the marginal worker. Hence, the firm's outside option is not remaining idle, but rather producing with one worker less. This can be implemented in two ways: either by defining firm's surplus to be $V^{J}\left(H_{i}\right)-V^{J}\left(H_{i}-1\right)$ or by taking the derivative of $V^{J}$ with respect to $H_{i}$ and considering this to be the contribution of the marginal worker. We will use the latter approach, as it is consistent with the assumption of a continuum of worker/consumers.

The multi-worker firm's individual bargaining problem is:

$$
\max _{w_{I}} \beta \ln \left[V_{I}^{E}-V^{U}\left(\theta_{\mu}\right)\right]+(1-\beta) \ln \frac{\partial V_{I}^{J}\left(H_{i}\right)}{\partial H_{i}} .
$$

To obtain an expression for firm's surplus, note that the individually bargaining firm is free to formulate its labor demand function. Hence, we can use the envelope condition of the firm's problem (5) in conjunction with the first order condition (10) to obtain:

$$
\frac{\partial V_{I}^{J}\left(H_{i}\right)}{\partial H_{i}}=\frac{1}{r+\chi}\left(\frac{\sigma-1}{\sigma} A_{i} P_{i}^{I}\left(H_{i}\right)-\frac{\partial w_{I}}{\partial H_{i}} H_{i}-w_{I}\left(H_{i}\right)\right)
$$

\footnotetext{
${ }^{7}$ See Stole and Zwiebel (1996a) for an intuitive discussion.
} 
The individual worker's surplus is standard:

$$
V_{I}^{E}-V^{U}\left(\theta_{\mu}\right)=\frac{w_{I}\left(H_{i}\right)-r V^{U}\left(\theta_{\mu}\right)}{r+\chi} .
$$

Substituting the expressions for worker's and firm's surplus (12) and (13) into the first order condition of (11) leads to a first-order linear differential equation in the wage.

$$
w_{I}\left(H_{i}\right)=(1-\beta) r V^{U}\left(\theta_{\mu}\right)+\frac{\sigma-1}{\sigma} \beta P_{i}^{I}\left(H_{i}\right) A-\beta H_{i} \frac{\partial w_{I}}{\partial H_{i}}
$$

It is straightforward to confirm that (14) has solution ${ }^{8}$ :

$$
\frac{w_{I}\left(H_{i}\right)}{P}=(1-\beta) r V^{U}\left(\theta_{\mu}\right)+\beta \frac{\sigma-1}{\sigma-\beta} A \frac{P_{i}^{I}\left(H_{i}\right)}{P} .
$$

Equation (15) is the wage curve.

\subsubsection{Firm-level Equilibrium}

Under individual bargaining, the firm is free to choose its optimal employment level. Hence, the firm formulates a labor demand curve from its optimization problem (5)-(9). The labor demand function of the individually bargaining firm is found by combining (10) with the envelope condition, using the definition of demand elasticity and the fact that the bargained wage adjusts to changes in the employment level according to $\frac{\partial w_{I}}{\partial H_{i}} \frac{H_{i}}{P}=-A \frac{\beta}{\sigma} \frac{\sigma-1}{\sigma-\beta} \frac{P}{P}$ :

$$
\frac{w_{I}\left(H_{i}\right)}{P}=\frac{\sigma-1}{\sigma-\beta} A \frac{P_{i}^{I}\left(H_{i}\right)}{P}-\frac{\Phi_{V}}{q\left(\theta_{\mu}\right)}\left(\frac{r+\chi}{1-\delta}\right)
$$

Firm-level equilibrium employment $H_{i}$ and the corresponding wage $w_{I}\left(H_{i}\right)$ may be obtained at the intersection of the labor demand curve (16) and the wage curve (15). Formally, the firm-level equilibrium employment is described implicitly by:

$$
A \frac{P_{i}^{I}\left(H_{i}\right)}{P}=\frac{\sigma-\beta}{\sigma-1}\left[\frac{r V^{U}\left(\theta_{\mu}\right)}{P}+\frac{1}{1-\beta} \frac{\Phi_{V}}{q\left(\theta_{\mu}\right)}\left(\frac{r+\chi}{1-\delta}\right)\right]
$$

The partial equilibrium real wage can be found by substituting (17) back into (16).

$$
\frac{w_{I}\left(\theta_{\mu}\right)}{P}=\frac{r V^{U}\left(\theta_{\mu}\right)}{P}+\frac{\beta}{1-\beta} \frac{\Phi_{V}}{q\left(\theta_{\mu}\right)}\left(\frac{r+\chi}{1-\delta}\right)
$$

\footnotetext{
${ }^{8}$ We follow Cahuc, Marque, and Wasmer (2004) in pinning down the constant by the condition that an individual firm's labor costs converge to zero as firm-level employment goes to zero, $\lim _{H_{i} \rightarrow 0} H_{i} w_{I}\left(H_{i}\right)=0$.
} 
The firm-level equilibrium (17) and (18) involves overhiring. As defined by Stole and Zwiebel (1996), firms engage in overhiring if they hire workers beyond the point at which employment costs (wages plus hiring costs) are covered by marginal revenue product. This can be shown by combining (17) and (18) to obtain:

$$
\underbrace{\frac{\sigma}{\sigma-\beta}}_{\text {erhiring term }} \underbrace{\frac{\sigma-1}{\sigma} A \frac{P_{i}^{I}\left(H_{i}\right)}{P}}_{\text {MRP }}=\underbrace{\frac{w_{I}\left(\theta_{\mu}\right)}{P}+\frac{\Phi_{V}}{q\left(\theta_{\mu}\right)}\left(\frac{r+\chi}{1-\delta}\right)}_{\text {employment costs }}
$$

As can be seen from (19), the overhiring term $\frac{\sigma}{\sigma-\beta}>1$ gives the magnitude of the overhiring externality, as it describes the factor by which employment costs exceed MRP. The reason that firms are willing to hire such 'loss-making' workers is the fact that adding an additional worker lowers MRP and hence lowers wages for all workers. Hence, hiring an additional worker imposes an externality on all other workers, which firms can exploit to depress wages.

Finally, we can also compute the individually bargaining firm's optimal employment explicitly by combining (17) with the demand curve facing firm $i$ (6),

$$
H^{I}\left(\theta_{\mu}\right)=A^{\sigma-1} I\left\{\frac{\sigma-\beta}{\sigma-1}\left[\frac{r V^{U}\left(\theta_{\mu}\right)}{P}+\frac{1}{1-\beta} \frac{\Phi_{V}}{q\left(\theta_{\mu}\right)}\left(\frac{r+\chi}{1-\delta}\right)\right]\right\}^{-\sigma} .
$$

\subsection{Collective Bargaining}

Under collective bargaining, all workers employed by a given firm form a coalition. Members of the coalition agree to negotiate wages together. We assume that workers have the power to negotiate over hiring ${ }^{9}$, so that the two negotiated quantities are the wage $w_{C}$ and the steady-state employment level $H_{i}$. In the event of disagreement, the firm is dissolved ${ }^{10}$, so that the firm's surplus is equal to its total value.

\footnotetext{
${ }^{9}$ In this efficient bargaining setup firms and unions negotiate over steady state wages and employment. In a right-to-manage setup it is straightforward to bargain about current wages and let firms optimally decide about future vacancies. Our results are not substantially affected by the choice of union bargaining regime, experiments for the right to manage framework are available upon request.

10 Recently, there has been renewed interest in the appropriate specification of the threatpoint in Nash bargaining in a job matching model. Our results are robust to alternative assumptions about the threatpoint, we have computed versions with one-period production losses and dissolution of the match in addition to the results presented here. Fujita and Ramey (2005) show the importance of distinguishing between job flows and worker flows for the business cycle. However, for our steady state analysis results are robust.
} 
Formally, the multi-worker firm collective bargaining problem is:

$$
\max _{w_{C}, H_{i}} \beta \ln \left\{H_{i}\left[V^{E}\left(\theta_{\mu}\right)-V^{U}\left(\theta_{\mu}\right)\right]\right\}+(1-\beta) \ln V_{C}^{J}\left(H_{i}\right)
$$

From (5), the steady-state value of a collective bargaining firm with $H_{i}$ workers is given by:

$$
V_{C}^{J}\left(H_{i}\right)=\frac{1}{r+\delta}\left[A P_{i}^{C}\left(Y_{i}\right) H_{i}-w_{C} \cdot H_{i}-\frac{\Phi_{V} P \widetilde{\chi}}{q\left(\theta_{\mu}\right)} H_{i}\right]
$$

The collective workers' surplus is standard, and can be obtained by multiplying the expression in (13) by firm-level employment. Taking the first order conditions with respect to the collective bargaining wage and employment levels and then finding their intersection yields an expression for the collectively bargained real wage, as well as an implicit expression for the collectively bargained level of employment.

$$
\begin{gathered}
\frac{w_{C}\left(\theta_{\mu}\right)}{P}=\left[1+\frac{\beta}{\sigma-1}\right] \frac{r V^{U}\left(\theta_{\mu}\right)}{P}+\frac{\beta}{\sigma-1} \frac{\Phi_{V}}{q\left(\theta_{\mu}\right)} \tilde{\chi} \\
A \frac{P_{i}^{C}\left(\theta_{\mu}\right)}{P}=\frac{\sigma}{\sigma-1}\left[\frac{r V^{U}\left[\theta_{\mu}\right]}{P}+\frac{\Phi_{V}}{q(\theta)} \tilde{\chi}\right]
\end{gathered}
$$

We can also compute the collectively bargaining firm's optimal employment explicitly by combining (23) with the demand curve facing firm $i$ (6).

$$
H_{i}^{C}\left(\theta_{\mu}\right)=\left\{\frac{\sigma}{\sigma-1}\left[\frac{r V^{U}\left(\theta_{\mu}\right)}{P}+\frac{\Phi_{V}}{q\left(\theta_{\mu}\right)} \tilde{\chi}\right]\right\}^{-\sigma} A^{\sigma-1} I
$$

\subsection{Reservation Utilities}

In order to complete the description of firm-level equilibrium, it is necessary to derive expressions for the reservation values of unemployment. Recall that firms are atomistic. Hence, when calculating the reservation value of unemployment, workers assume that if they were to loose their current job, they would almost surely [i.e. with probability one] not find a job in their old firm. This implies that only the aggregate mix of bargaining institutions $\mu$ is relevant for the reservation value of unemployment. When all firms in the economy choose individual bargaining, so that $\mu=0$, the reservation value of unemployment can be found by combining (1) and (2) with the individual bargaining wage equation (18):

$$
\frac{r V^{U}\left(\theta_{I}\right)}{P}=b+\frac{\beta}{1-\beta} \frac{\Phi_{V}}{1-\delta} \theta_{I}
$$


Similarly, when all firms in the economy choose collective bargaining, so that $\mu=1$, the reservation value of unemployment becomes

$$
\frac{r V^{U}\left(\theta_{C}\right)}{P}=\frac{(r+\chi)(\sigma-1)}{(r+\chi)(\sigma-1)-\beta \theta_{C} q\left(\theta_{C}\right)} b+\frac{\beta \theta_{C} q\left(\theta_{C}\right)}{(r+\chi)(\sigma-1)-\beta \theta_{C} q\left(\theta_{C}\right)} \frac{\Phi_{V}}{q\left(\theta_{C}\right)} \tilde{\chi}
$$

where $\theta_{C} \equiv \theta_{1}$. Finally, the closed form solution for arbitrary $\mu$ is derived in the appendix and given by:

$$
\begin{aligned}
\frac{r V^{U}\left(\theta_{\mu}\right)}{P}= & \frac{(r+\chi)(\sigma-1)}{(r+\chi)(\sigma-1)-\beta \mu \theta_{\mu} q\left(\theta_{\mu}\right)} b \\
& +\frac{\beta \Phi_{V} \theta_{\mu}}{(r+\chi)(\sigma-1)-\beta \mu \theta_{\mu} q\left(\theta_{\mu}\right)}\left[\mu \widetilde{\chi}+\frac{(1-\mu)(\sigma-1)}{1-\beta}\left(\frac{r+\chi}{1-\delta}\right)\right]
\end{aligned}
$$

\section{General Equilibrium}

\subsection{Short-run General Equilibrium}

Now, we determine the 'short-run' general equilibrium for each bargaining institution, taking as given the demand elasticity $-\sigma$ facing the firms. In our setting, this is equivalent to pinning down all equilibrium variables as functions of the degree of competition $\sigma$. This will allow us to determine the impact of increasing competition on equilibrium unemployment and wages.

Definition 1: Short-run General Equilibrium

A short-run general equilibrium is defined for given demand elasticity $-\sigma$ and parameters $\left(\beta, \sigma, b, \Phi_{V}, \delta, \chi, r, A\right)$ as a value of $\theta_{\mu}$ which:

(i) is a firm-level equilibrium satisfying (18) and (20) for individual-bargaining firms, (22) and (24) for collective-bargaining firms, and (27).

(ii) satisfies the aggregate resource constraint that aggregate income be equal to aggregate production, valued at equilibrium prices:

$$
I=(1-\mu)\left[\frac{P_{i}^{I}\left(H_{i}\right)}{P} A H_{i}^{I}\left(\theta_{\mu}\right)\right]+\mu\left[\frac{P_{i}^{C}\left(H_{i}\right)}{P} A H_{i}^{C}\left(\theta_{\mu}\right)\right]
$$

Substituting equilibrium prices (17) and (23), and employments (24) and (20) into (28) leads immediately to the short-run equilibrium condition

$$
\begin{aligned}
A^{1-\sigma}= & (1-\mu)\left[\frac{\sigma-\beta}{\sigma-1}\left(\frac{r V^{U}\left(\theta_{\mu}\right)}{P}+\frac{1}{1-\beta} \frac{\Phi_{V}}{q\left(\theta_{\mu}\right)} \frac{r+\chi}{1-\delta}\right)\right]^{1-\sigma} \\
& +\mu\left[\frac{\sigma}{\sigma-1}\left(\frac{r V^{U}\left(\theta_{\mu}\right)}{P}+\frac{\Phi_{V}}{q\left(\theta_{\mu}\right)} \tilde{\chi}\right)\right]^{1-\sigma}
\end{aligned}
$$


where $\frac{r V^{U}\left[\theta_{\mu}\right]}{P}$ is taken from equation (27).

When $\mu=0$, so that all firms engage in individual bargaining, we obtain the equilibrium condition:

$$
A=\frac{\sigma-\beta}{\sigma-1}\left(b+\frac{\beta}{1-\beta} \frac{\Phi_{V}}{1-\delta} \theta_{I}+\frac{1}{1-\beta} \frac{\Phi_{V}}{q\left(\theta_{I}\right)}\left(\frac{r+\chi}{1-\delta}\right)\right)
$$

The short-run general equilibrium condition for individual bargaining (30) is monotonically increasing in $\theta_{I}$, so that existence of equilibrium is guaranteed if

$$
A>\frac{\sigma-\beta}{\sigma-1} b .
$$

When $\mu=1$, so that all firms engage in collective bargaining, we have:

$$
A=\frac{(r+\chi) \sigma}{(r+\chi)(\sigma-1)-\beta \theta_{C} q\left(\theta_{C}\right)}\left[b+\frac{\Phi_{V}}{q\left(\theta_{C}\right)} \tilde{\chi}\right]
$$

The RHS of the collective bargaining short-run general equilibrium condition (32) is also monotonically increasing in $\theta_{C}$, so that existence of equilibrium is guaranteed if

$$
A>\frac{\sigma}{\sigma-1} b .
$$

When the economy approaches full competition [as $\sigma \rightarrow \infty$ ], (31) and (33) reduce to the standard condition $A>b$ that workers' productivity be greater in employment than in unemployment.

Equation (29) ( including its special cases (30) and (32)) describes the short run equilibria, since for each level of competition $\sigma$ and mix of bargaining institutions $\mu$ facing the individual firm it describes the equilibrium labor market tightness $\theta_{\mu}$ as a function of parameters. These equilibrium conditions are key, since they relate the degree of competition $\sigma$ to short-run equilibrium labor market tightness $\theta_{\mu}$. Once we have $\theta_{\mu}(\sigma)$, we can obtain the equilibrium unemployment rate from the Beveridge curve:

$$
u(\sigma)=\frac{\chi}{\chi+\theta_{\mu}(\sigma) q\left[\theta_{\mu}(\sigma)\right]}
$$

The remainder of equilibrium variables are found as follows: Given the total number of agents in the economy $N$, we can find equilibrium aggregate employment as $\mu H_{i}^{C}(\sigma)+(1-\mu) H_{i}^{I}(\sigma)=N[1-u(\sigma)]$. We will find it convenient to normalize $N=1$. With $H_{i}^{C}(\sigma)$ and $H_{i}^{I}(\sigma)$ in hand, we can find aggregate output and subsequently the equilibrium quantity of good $i$, and of course equilibrium prices $P_{i}^{C}(\sigma)$ and $P_{i}^{I}(\sigma)$, all in terms of the given degree of competition. 


\subsection{Long-run General Equilibrium}

Now we are ready to endogenize the degree of competition. In the long-run, firms may enter each industry by paying a real entry $\operatorname{cost} \Phi_{E}$. Entry by firms will continue until profits net of entry costs within each industry have been competed down to zero. The free entry condition (35) states that the entry cost (administrative cost of entry plus the cost of hiring the steady-state stock of workers) must be amortized by profits over the firm's expected lifespan.

$$
\Phi_{E}\left(\sigma^{*}\right)+\frac{\Phi_{V}}{q\left(\theta_{\mu}\right)} H_{i}\left(\sigma^{*}\right)=V_{k}^{J}\left(\sigma^{*}\right)
$$

where $V_{k}^{J}(\sigma)$ is the steady-state equilibrium value of the firm using bargaining institution $k \in\{I, C\}$ when demand elasticity is $\sigma$. Equation (35) closes the long-run equilibrium. It implicitly determines the endogenous degree of competition $\sigma^{*}$ in long-run equilibrium and defines a negative relationship between barriers to entry and the degree of competition in long-run equilibrium. Hence, an increase in entry barriers of either form leads to a long-run equilibrium decrease in the demand elasticity, $\sigma^{*}$, faced by firms ${ }^{11}$.

To calibrate the model, we must pin down entry costs using the data. We allow the entry barriers summarized by $\Phi_{E}$ to take two complementary forms, time and pecuniary costs. Table 1 shows two sets of data on the time dimension of entry, collected by Logotech, S.A. for the OECD (as reported in Fonseca, et. al. (2001)) and Djankov, et. al. (2002). Both series report the time it takes to satisfy all regulatory entry requirements and the number of procedures involved in entry. Also reported is an index derived by Fonseca, et. al (2001), which weights the time to enter by the number of procedures which must be completed per time unit. Table 1 also reproduces data from Djankov, et. al. (2002) on the official fees which must be paid in order to obtain all licenses and permits, as a percentage of annual per capita GDP.

We combine the fee and regulatory delay measures to obtain a single quantification of barriers to entry. We convert the regulatory delay (measured in months)

\footnotetext{
${ }^{11}$ It is true that we are modifying a preference parameter here. In an early version of the paper (Ebell and Haefke, 2003) we microfounded the number of firms based on Galí (1995) and on Galí and Zilibotti (1995). Results were almost indistinguishable but the extra level of complexity was substantial. For the sake of clarity we follow Blanchard and Giavazzi (2003) and directly vary $\sigma$ now.
} 
into a pecuniary opportunity cost consisting of lost income during the set-up period. Formally, total barriers to entry are found as:

$$
\Phi_{E}(\sigma)=(d+f) \cdot I(\sigma) .
$$

where $d$ is the regulatory delay and $f$ are entry fees as a share of aggregate monthly income.

\subsection{Income Taxes}

In order to run policy experiments, we must also take into account that unemployment benefits must generally be financed by taxes. We impose equal magnitude income and payroll taxes, which are just large enough to finance the equilibrium expenditures on unemployment benefits:

$$
\left(\tau_{I}+\tau_{P}\right) \frac{w}{P} \cdot(1-u)=b u
$$

It is straightforward to confirm that the short-run equilibrium condition for individual bargaining becomes ${ }^{12}$ :

$$
A=\frac{\sigma-\beta}{\sigma-1}\left(\frac{1+\tau_{P}}{1-\tau_{I}} b+\frac{\beta}{1-\beta} \frac{\theta_{I} \Phi_{V}}{1-\delta}+\frac{1}{1-\beta} \frac{\Phi_{V}}{q\left(\theta_{I}\right)} \frac{r+\chi}{1-\delta}\right)
$$

while the corresponding equation for collective bargaining becomes:

$$
A=\frac{\sigma(r+\chi)}{(r+\chi)(\sigma-1)-\beta \theta_{C} q\left(\theta_{C}\right)}\left[\frac{1+\tau_{P}}{1-\tau_{I}} b+\frac{\Phi_{V}}{q\left(\theta_{C}\right)} \tilde{\chi}\right]
$$

\section{Quantitative Results}

We are now in a position to calibrate our model and approach the first of our two quantitative questions. We first explain in detail how we calibrate the basic model to match a set of labor market data from the U.S.. Then, for this calibration we compare the impact of increasing competition on equilibrium labor market outcomes under collective and under individual bargaining. That is, we examine by how much unemployment decreases and by how much wages increase due to an increase in our measure of competition [demand elasticity $\sigma$ ] under each bargaining framework. We will find that the impact of competition on unemployment is much stronger under collective than under individual bargaining.

\footnotetext{
${ }^{12}$ The balanced-budget version of the model is a straightforward extension of the basic model. Complete derivations are available from the authors upon request.
} 


\subsection{Calibration}

We calibrate the individual bargaining version of the model to US data. We will then use the parameters obtained to solve the collective bargaining model. One model period is one month. All parameters are reported in Table 2. We use estimates from the literature to guide our choices for the first group of parameters. The bargaining power of workers, $\beta$, has recently been estimated between $20 \%$, (Cahuc, Gianella, Goux and Zylberberg, 2002) and 50\% (Abowd and Allain, 1996, Yashiv, 2001). Petrongolo and Pissarides (2001) report $\eta$, the elasticity of the matching function with respect to unemployment, to be in the range of [0.5;0.7]. We set $\beta=\eta=0.5$, thus choosing standard values and imposing the Hosios (1990) condition. For simplicity, we normalize the level of technology $A$ to unity. Our choice for the annualized real interest rate approximates its average value in the 1990's. We choose a replacement rate of $30 \%{ }^{13}$

We choose the remaining parameters to match some stylized labor market data for the U.S. during the period 1989-2002. Specifically, we replicate an unemployment rate of $5.5 \%$ and set the job finding rate to be 0.45 following Shimer (2005). We choose the firm's matching rate so that the vacancy duration is 4.2 months (den Haan et al, 2000). Our choices for unemployment duration and vacancy duration restrict US equilibrium labor market tightness to be $\theta=\frac{\lambda_{w}}{\lambda_{f}}=1.89$, where $\lambda_{w}$ and $\lambda_{f}$ are the matching rates of workers and firms respectively. ${ }^{14}$ This figure looks high at first glance. However, before comparing it to standard one-worker firm models and data it is necessary to adjust for the fact that firms open as many vacancies as necessary in order to fulfill their hiring needs in expectation. If we multiply the equilibrium tightness $\theta$ with the firm matching rate we find a ratio of open jobs to unemployed of $45 \%$. The equality of tightness with the job-finding rate is also in line with the findings of Shimer (2005). Finally, the scaling parameter of the matching function $s$ must satisfy $s=\frac{\lambda_{w}}{\theta^{1-\eta}}$.

\footnotetext{
${ }^{13}$ Rather than introducing heterogeneity among unemployed by cutting off their benefits, we prefer to adjust the generosity of unemployment compensation. This is standard, as is the choice of a $30 \%$ replacement ratio for the U.S. In Section 7.2.2 we show the robustness of our results to alternative calibrations.

${ }^{14}$ Note that the value of $\theta$ does not fully describe long-run equilibrium, as long as entry costs $\Phi_{V}$ are allowed to vary.
} 
The exogenous total separation rate $\chi=0.026$, is pinned down by the Beveridge curve in conjunction with our values for unemployment and unemployment duration. We set $\delta=0.8 \%$, so that the monthly probability that a firm will cease to exist implies an annual firm survival rate of $90.8 \%$. This matches the average five-year survival probability reported by Wagner (1994) and is in line with the four-year firm survival probabilities reported in Mata and Portugal (1994), which imply monthly exit rates between 0.6 and $1.4 \%$.

We are left with the following long-run equilibrium condition which relates vacancy posting costs $\Phi_{V}$ to firm's demand elasticity $\sigma .^{15}$

$$
A=\frac{\sigma^{*}-\beta}{\sigma^{*}-1}\left(\frac{1+\tau_{P}}{1-\tau_{I}} b+\frac{\beta}{1-\beta} \frac{\theta_{I} \Phi_{V}}{1-\delta}+\frac{1}{1-\beta} \frac{\Phi_{V}}{q\left(\theta_{I}\right)} \frac{r+\chi}{1-\delta}\right)
$$

We close the model by choosing a value for $\Phi_{V}$. We choose that level of vacancy posting costs which leads to a long-term U.S. equilibrium unemployment rate of 5.5 $\%$. This yields a value of $\Phi_{V}=0.33$, so that hiring costs per worker are $\frac{1}{\lambda_{f}} \Phi_{V}=1.4$ units of output, which corresponds to about $12 \%$ of annual payroll. ${ }^{16}$ Finally, our calibrations are for a balanced budget version of the model in which unemployment benefits are financed by equal magnitude income and payroll taxes $\left(\tau_{I}, \tau_{P}\right)$. In the US model economy, income and payroll taxes of $0.9 \%$ are necessary to finance unemployment benefits.

\subsection{A little bit of competition goes a long way}

We begin by comparing the implications of exogenously varying the degree of product market competition under collective bargaining to those under individual bargaining. Figure 4 shows that the behavior of two key variables - unemployment and workers' share of match surplus are strikingly different under the two bargaining regimes. Increasing the degree of product market competition leads to dramatic decreases in unemployment levels under collective bargaining. In contrast, increasing product market competition under individual bargaining has only negligible effects on unemployment. The reason for this discrepancy is due to the

\footnotetext{
${ }^{15}$ Recall that $\theta$ is pinned down by firm and worker matching rates so that the only free variables in equation 40 are $\sigma^{*}$ and $\Phi_{V}$, where $\sigma^{*}$ itself is determined by the free entry condition (35).

${ }^{16}$ This is somewhat lower than Hamermesh and Pfann (1996), who report fixed hiring costs in the range of $20 \%$ to $100 \%$ of annual payroll expenses for a worker. Their data pre-dates the advent of the internet era, however, which may have made search substantially cheaper.
} 
overhiring effect of individual bargaining, as explained in our companion paper Ebell and Haefke (2006) ${ }^{17}$. Regardless of bargaining framework, the first principles effect of increasing competition should be an expansion of output, and hence an expansion of hiring and vacancy creation. Under individual bargaining, however, an additional countervailing overhiring effect exists. Briefly, under individual bargaining all workers are treated as the marginal worker, so that if the marginal product of labor is decreasing, then the wages of all workers can be depressed by expanding employment. At low levels of competition, the overhiring effect is especially strong, and serves to counteract the positive impact on unemployment due to output expansion.

The second key variable whose behavior is strongly dependent on the bargaining framework is the worker's share of surplus component of real wages. This will be important in the next section, because it is precisely the workers' share of surplus which is crucial for determining whether a given bargaining framework can be supported as a symmetric Nash equilibrium.

The behavior of wages and profits makes clear the distributional effects of the choice of bargaining regime. Under individual bargaining firms always earn higher profits. The reason is that under individual bargaining, firms choose the steadystate employment level, giving them an additional degree of freedom when maximizing profits. Collective bargaining offers workers higher real wages at low levels of competition, but that advantage is reversed when competition increases sufficiently, mirroring the behavior of the profit-based collective bargaining surplus share received by workers.

\subsection{Policy Experiment I}

Now we are in a position to address our first quantitative question: By how much would unemployment decline if entry costs were reduced from the high continental European average levels to low U.S. levels? We answer this question for each of the two bargaining regimes examined, individual and collective, and find that each bargaining regime leads to strikingly different answers. In order to perform

\footnotetext{
${ }^{17}$ The overhiring effect was first described in a partial equilibrium setting by Stole and Zwiebel (1996).
} 
these experiments we proceed to find the long-run equilibria for both low US and high continental European entry costs, under each of the two possible bargaining regimes. This is illustrated in Figure 5. As described in section 4.2, the long-run equilibrium level of competition is that at which firms' profits are just high enough to recoup their entry costs. In each panel the solid blue line gives per-firm profits at each level of competition, while the dashed green line gives the entry costs which must be amortized each period, taking firms' exit probability into account. Long-run equilibrium is found at the intersection of these two lines. Tables 3 and 4 summarize the results of the experiments. Under individual bargaining, a drop in EU entry costs to U.S. levels would cause only a negligible drop in unemployment, from $5.64 \%$ to $5.50 \%$. Under collective bargaining, however, decreasing EU entry costs to U.S. levels would lead to a substantial decline of more than 5 percentage points, from $8.91 \%$ to $3.83 \%$. Hence the employment effects of product market deregulation depend crucially on the bargaining regime.

\section{Optimal Bargaining Institution}

In the previous sections, we characterized the short-run general equilibrium, taking as given the share $\mu$ of firms which engage in collective bargaining. We now examine how and when collective bargaining coalitions will arise endogenously, thereby determining $\mu$ endogenously. Workers at each firm are free to choose whichever bargaining institution they prefer. The only restriction is that all workers of a firm must agree on [or submit to a majority vote] a bargaining structure. Given that all workers are identical, all decisions on the bargaining institution are reached with unanimity, so that this restriction is not at all limiting. ${ }^{18}$

We will focus first on symmetric Nash equilibria, in which all firms in the economy choose the same bargaining institution. We do not, however, impose economywide unanimity over bargaining institutions as an a priori restriction. This implies that firms and/or industries are free to 'deviate' from the remaining firms

\footnotetext{
${ }^{18}$ Note that it is not possible to distinguish between firm-level and industry-level bargaining in the Dixit-Stiglitz monopolistic competition setup. The reason is that each firm produces a differentiated product as a monopolist, so that industry size is always one. For a recent analysis that extends our setup to union coordination see Delacroix (2006).
} 
in the economy by choosing a distinct bargaining regime. In this sense, a symmetric Nash equilibrium is one in which no firm finds it optimal to deviate from the bargaining regime which has also been (optimally) adopted by all other firms in the economy.

In a second step, we move on to consider mixed equilibria, in which any fraction $\mu \in(0,1)$ of collective bargaining firms coexist with the fraction $1-\mu$ of individual bargaining firms. We will find that mixed equilibria exist and turn out to be important when defining the transition dynamics of a product market deregulation.

\subsection{Symmetric Nash Equilibria}

Symmetric Nash equilibria are those in which all firms in the economy find it optimal to choose the same bargaining institution. In the case of a symmetric collective bargaining Nash equilibrium, this would imply that all workers in each firm find collective bargaining preferable to individual bargaining, given that all other workers in all other firms also adopt collective bargaining ${ }^{19}$.

\section{Definition 2: Stability of collective bargaining}

For a given degree of competition $\sigma$, collective bargaining is a symmetric Nash equilibrium if a unilateral deviation to individual bargaining is not optimal. This is the case if:

(i) Each of the employed workers receives a higher utility under collective bargaining, given that all other workers in all other firms also engage in collective bargaining, than he/she would receive by deviating to individual bargaining. Formally:

$$
V_{C}^{E}\left(\theta_{C}\right) \geq V_{I}^{E}\left(\theta_{C}\right)
$$

or (iia) A deviation to individual bargaining would be profitable for each employed worker:

$$
V_{I}^{E}\left(\theta_{C}\right) \geq V_{C}^{E}\left(\theta_{C}\right)
$$

but (iib) the total expected utility loss due to release of workers into unemployment due to the change in bargaining institution exceeds the total expected utility gain due to the

\footnotetext{
${ }^{19}$ Note that it is straightforward to add an explicit cost of unionization here. Under the assumption that union dues have to be paid by employed and unemployed workers they wash out of the surplus and have no effect on the wage bargaining. In such a case union dues appear only in the stability conditions (41) and (42). For simplicity we set them to zero.
} 
change in bargaining institution:

$$
\begin{aligned}
& {\left[H_{i}^{C}\left(\theta_{C}\right)-H_{i}^{I}\left(\theta_{C}\right)\right]\left[V_{C}^{E}\left(\theta_{C}\right)-V^{U}\left(\theta_{C}\right)\right] } \\
\geq & H_{i}^{I}\left(\theta_{C}\right)\left[V_{I}^{E}\left(\theta_{C}\right)-V_{C}^{E}\left(\theta_{C}\right)\right]
\end{aligned}
$$

The first part of the definition is obvious: no worker will ever be in favor of deviating to individual bargaining if it decreases his utility. The second part is more subtle: even if a deviation were profitable for every worker who retains his job, it may be the case that the transition from collective to individual bargaining would involve a decrease in firm-level employment, and hence the release of some measure of workers into unemployment. Essentially, part (iib) states that a deviation to individual bargaining will only take place if it is possible for the retained workers to compensate the released workers [in expectation] for their utility loss. Alternatively, one can think of the dismissals as being random, so that risk neutral workers will only choose to deviate if their expected utility improves.

The corresponding definition for individual bargaining symmetric Nash equilibrium is given next.

\section{Definition 3: Stability of individual bargaining}

For a given degree of competition $\sigma$, individual bargaining is a symmetric Nash equilibrium if a unilateral deviation to collective bargaining is not optimal. This is the case if:

(i) Each of the employed workers receives a higher utility under individual bargaining, given that all other workers in all other firms also engage in individual bargaining, than she would receive if her firm were to deviate to collective bargaining. Formally:

$$
V_{I}^{E}\left(\theta_{I}\right) \geq V_{C}^{E}\left(\theta_{I}\right)
$$

or (iia) A deviation to collective bargaining would be profitable for each employed worker

$$
V_{C}^{E}\left(\theta_{I}\right) \geq V_{I}^{E}\left(\theta_{I}\right)
$$

but (iib) the total expected utility loss due to release of workers into unemployment due to the change in bargaining institution exceeds the total expected utility gain due to the change in bargaining institution:

$$
\begin{aligned}
& {\left[H_{i}^{I}\left(\theta_{I}\right)-H_{i}^{C}\left(\theta_{I}\right)\right]\left[V_{I}^{E}\left(\theta_{I}\right)-V^{U}\left(\theta_{I}\right)\right] } \\
\geq & H_{i}^{C}\left(\theta_{I}\right)\left[V_{C}^{E}\left(\theta_{I}\right)-V_{I}^{E}\left(\theta_{I}\right)\right]
\end{aligned}
$$


The following lemmas establish sufficient conditions for a symmetric Nash equilibrium.

Lemma 1: If $w_{k}\left(\theta_{k}\right) \geq w_{j}\left(\theta_{k}\right)$, where $k \neq j$ are two distinct bargaining institutions, then bargaining institution $k$ is a symmetric Nash equilibrium.

Proof: By Definitions 2 and 3, bargaining institution $k$ is a symmetric Nash equilibrium.if $V_{k}^{E}\left(\theta_{k}\right) \geq V_{j}^{E}\left(\theta_{k}\right)$, for all alternative bargaining institutions $j$. From (1), we know that:

$$
V_{k}^{E}\left(\theta_{\mu}\right)=\frac{1}{r+\chi}\left[w_{k}\left(\theta_{\mu}\right)+\chi V^{U}\left(\theta_{\mu}\right)\right]
$$

so that $V_{k}^{E}\left(\theta_{\mu}\right) \geq V_{j}^{E}\left(\theta_{\mu}\right)$ if and only if $w_{k}\left(\theta_{\mu}\right) \geq w_{j}\left(\theta_{\mu}\right)$ for any $\mu \in[1,0]$.

Lemma 2: If the workers' share of bargaining surplus under bargaining regime $k$ is greater than the corresponding surplus under bargaining regime $j$, where $k \neq j$ are two distinct bargaining institutions, then bargaining institution $k$ is a symmetric Nash equilibrium.

Proof: By Lemma 1, bargaining institution $k$ is a symmetric Nash equilibrium.if $w_{k}\left(\theta_{k}\right) \geq$ $w_{j}\left(\theta_{k}\right)$, for any alternative bargaining institution $j$. Since the reservation utility is the same regardless of the firm's own bargaining regime, $w_{k}\left(\theta_{k}\right) \geq w_{j}\left(\theta_{k}\right)$ if and only if $w_{k}\left(\theta_{k}\right)-$ $r V^{U} \geq w_{j}\left(\theta_{k}\right)-r V^{U}$, which establishes the claim.

Lemma 1 makes clear that the higher wage bargaining institution is always a symmetric Nash equilibrium. Current workers would not benefit from the increased hiring that the lower-wage institution would entail [they already have jobs]. Also, firms are atomistic with respect to the economy, so that any firmlevel decision will have no impact on aggregate labor market tightness $\theta_{\mu}$ or on the distribution of firms across bargaining regimes $\mu$. Hence, workers are correct in neglecting the impact of their own choice of bargaining institution on their probability of being rehired out of a future unemployment spell, on their future wage in a new job, and hence on the reservation value of unemployment. Effectively, this implies that workers may choose to 'free-ride' on the aggregate choice of bargaining institution.

Lemma 2 establishes that the workers' wage preference is equivalent to the workers' preference for bargaining surpluses. Hence, the bargaining regime which 
offers workers a higher bargaining surplus is also that which offers a higher wage, and is hence a symmetric Nash equilibrium.

Now, Lemma 3 translates the surplus condition of Lemma 2 into a sufficient condition on the level of competition. At sufficiently low levels of competition, collective bargaining is a symmetric Nash equilibrium, while at sufficiently high levels of competition, individual bargaining is a symmetric Nash equilibrium. The proof of Lemma 3 can be found in the appendix.

Lemma 3: (i) If $\sigma \leq 1+\frac{(1-\beta)(1-\delta)}{r+\chi}\left[b \frac{q\left(\theta_{C}\right)}{\Phi_{V}}+\tilde{\chi}\right]+\beta \frac{\theta_{C} q\left(\theta_{C}\right)}{r+\chi}$, then collective bargaining is a symmetric Nash equilibrium.

(ii) If $\sigma \geq 1+\frac{(1-\beta)(1-\delta)}{r+\chi}\left[b \frac{q\left(\theta_{I}\right)}{\Phi_{V}}+\tilde{\chi}\right]+\beta \frac{\theta_{I} q\left(\theta_{I}\right)}{r+\chi}$, then individual bargaining is a symmetric Nash equilibrium.

The following two subsections establish the bargaining equilibrium in two extreme cases: the perfect competition limit and the lowest level of competition which is consistent with equilibrium.

\subsubsection{Perfect Competition}

In the perfect competition limit, both individual and collective bargaining are symmetric Nash equilibria. IB is an equilibrium because it offers workers a positive surplus, while the $\mathrm{CB}$ surplus shrinks to zero. The intuition behind the higher surplus for individually bargaining workers is simple, yet subtle. Recall that collectively bargaining workers are essentially able to obtain a share of the firm's equilibrium profits. Under perfect competition, profits net of hiring costs converge to zero, so that the workers' wages converge to their reservation level $b$. Under individual bargaining, however, workers are still able to obtain a positive surplus, since their surplus is based on the workers' marginal value to the firm. In equilibrium, this marginal value is equal to the cost to hiring a worker. Hiring costs reach their peak under perfect competition. The reason is that output expansion [and the accompanying expansion in vacancy posting] means that labor market tightness $\theta$ is increasing in competition. For given hiring costs, this implies that replacing an individual worker is costliest under perfect competition, bringing an individual worker's total match surplus to its maximum value. Hence, under perfect competition, workers prefer the individual bargaining surplus, and consequently individ- 
ual bargaining. ${ }^{20}$

However, $\mathrm{CB}$ is also an equilibrium. If all firms in the economy are currently engaged in collective bargaining, workers will be indifferent between switching to the higher-wage IB equilibrium and remaining in the lower-wage CB equilibrium. The reason is that any wage gains are just outweighed by expected employment losses.

Proposition 1 formalizes the above arguments. The accompanying proof may be found in the appendix.

Proposition 1: In the perfect competition limit, both individual and collective bargaining are symmetric Nash equilibria. In addition, any share of collective bargaining firms $\mu \in(0,1)$ is also a Nash equilibrium.

\subsubsection{Imperfect Competition}

Under imperfect competition, in contrast, collective bargaining may indeed be the unique symmetric Nash equilibrium. Individual bargaining may be unstable, since workers will endogenously choose to form collective bargaining coalitions. We begin by examining the extreme case: the lowest level of competition which is consistent with existence of short-run general equilibrium under collective bargaining, $\sigma_{\min }$. This minimal degree of competition is found by taking the limit as $\theta_{c} \rightarrow 0$ of the collective bargaining equilibrium condition (32), yielding $\sigma_{\min } \equiv \frac{A}{A-b}$. Proposition 2 establishes that collective bargaining is a symmetric Nash equilibrium at $\sigma_{\min }$. The intuition is similar to that of Proposition 1. When choosing between bargaining institutions, workers effectively are choosing whether they prefer to receive the collective or the individual bargaining surplus. At very low levels of competition, firms' profits are large, and hence the workers' collective bargaining surplus is also large. In contrast, at low levels of competition the individual bargaining surplus is at its minimum, since this is also where hiring and vacancy posting are at their minimum levels, actually converging to zero as competition converges to its minimum level. Hence, the minimal level of competition, workers prefer the collective bargaining surplus, and consequently collective bargaining. The proof of Proposition

\footnotetext{
${ }^{20}$ Under right-to-manage collective bargaining, individual and collective bargaining are also both Nash equilibria in the perfect competition limit. The reason is that RTM wages converge to IB wages as demand elasticity approaches infinity, making workers indifferent between the two regimes.
} 
2 is in the appendix.

Proposition 2: In the imperfect competition limit $\sigma_{\min }$, collective bargaining is a symmetric Nash equilibrium.

Finally, Proposition 3 establishes a range of competition levels $\sigma$ such that collective bargaining will emerge for the special case of $\eta=\frac{1}{2}$. Formally, the proposition shows that when $\sigma$ is lower than a critical value $\widetilde{\sigma}_{C}$, then collective bargaining is guaranteed to be a symmetric Nash equilibrium.

Proposition 3: When matching elasticity $\eta=\frac{1}{2}$, there exists a critical value of product market competition [demand elasticity] $\widetilde{\sigma}_{C}$, so that collective bargaining is a symmetric Nash equilibrium for all $\sigma \leq \widetilde{\sigma}_{C}$.

The proof of Proposition 3 is found in the appendix. The intuition follows that presented above: at low levels of competition, monopoly rents and hence collective bargaining surplus is high, while individual bargaining surplus remains relatively low due to low values of labor market tightness. This is illustrated in the lower right hand panel of Figure 4, which shows collective and individual bargaining surpluses as functions of demand elasticity $\sigma$.

\subsection{Mixed Strategy Equilibria}

By mixed strategy equilibria, we mean a Nash equilibrium in which some fraction $\mu \in(0,1)$ of firms chooses collective bargaining coexists with a fraction $1-\mu$ of firms which chooses individual bargaining. We identify three possible mixed strategy equilibria:

\section{Mixed Equilibrium I}

A mixed strategy Nash equilibrium is a fraction $\mu$ of firms choosing collective bargaining such that:

$$
V_{I}^{E}\left(\theta_{\mu}\right)=V_{C}^{E}\left(\theta_{\mu}\right)
$$

In this case, wages and surpluses are equal under both bargaining institutions, so that neither the individual bargaining nor the collective bargaining workers wish to deviate from their current choice of bargaining institution.

\section{Mixed Equilibrium II}

A mixed strategy Nash equilibrium is a fraction $\mu$ of firms choosing collective 
bargaining such that:

$$
V_{I}^{E}\left(\theta_{\mu}\right) \leq V_{C}^{E}\left(\theta_{\mu}\right)
$$

and

$$
H_{i}^{C}\left(\theta_{\mu}\right)\left[V_{C}^{E}\left(\theta_{\mu}\right)-V^{U}\left(\theta_{\mu}\right)\right] \leq H_{i}^{I}\left(\theta_{\mu}\right)\left[V^{E}\left(I, \theta_{\mu}\right)-V^{U}\left(\theta_{\mu}\right)\right]
$$

In this case, the collective bargaining wage is higher. Nonetheless, workers who are currently employed in individual bargaining firms do not find it optimal to switch because the expected benefits due to high wages are outweighed by the expected utility loss due to layoffs.

\section{Mixed Equilibrium III}

A mixed strategy Nash equilibrium is a fraction of firms $\mu$ choosing collective bargaining such that:

$$
V_{C}^{E}\left(\theta_{\mu}\right) \leq V_{I}^{E}\left(\theta_{\mu}\right)
$$

and

$$
H_{i}^{I}\left(\theta_{\mu}\right)\left[V_{I}^{E}\left(\theta_{\mu}\right)-V^{U}\left(\theta_{\mu}\right)\right] \leq H_{i}^{C}\left(\theta_{\mu}\right)\left[V_{C}^{E}\left(\theta_{\mu}\right)-V^{U}\left(\theta_{\mu}\right)\right]
$$

Now it is the individual bargaining wage that is higher. However, workers who are currently employed in individual bargaining firms do not find it optimal to switch due to the expected job losses. Hence, both bargaining arrangements are stable given $\mu$ and $\theta_{\mu}$.

We will look for mixed equilibria in the quantitative section of the paper, and will indeed find that they are important for understanding the dynamics of product market deregulation.

\section{Quantitative Results with Endogenous Bargaining Insti- tutions}

\subsection{Nash Equilibria}

Next, we examine which bargaining institution will emerge endogenously under each entry cost regime. In particular, we check whether the necessary and sufficient conditions for a Nash equilibrium are satisfied for each of the four long-run equilibria described in section 5.3. First, we look for symmetric collective bargaining 
Nash equilibria using the wage criterion. The upper panels of Figure 6 illustrates that collective bargaining is a symmetric Nash equilibrium if $\sigma<11.1$, while individual bargaining is certain to be an individual bargaining equilibrium if $\sigma$ exceeds 15.1. ${ }^{21}$ This implies that collective bargaining is a symmetric Nash equilibrium under European entry costs, since workers' share of surplus is higher when competition takes its long-run equilibrium value $\sigma_{E U, C}=7.8$, so that the sufficient condition from Lemma 2 is satisfied. On the same grounds, individual bargaining is a symmetric Nash equilibrium under the high demand elasticity to which US entry costs lead.

The lower panels of Figure 6 consider the employment criterion. The lower left panel shows that although workers' deviation to IB would be profitable in wage terms whenever demand elasticity $\sigma$ exceeds 11.1 , the expected utility impact of the job losses involved would be large enough to outweigh the positive impact of wage gains for those workers who retain their jobs. As a result, workers will never find it optimal to deviate from a symmetric collective bargaining equilibrium, regardless of the degree of competition or equivalently regardless of the level of entry costs. Hence, in our calibrated model, collective bargaining is a stable economywide institution at all levels of competition.

The right two panels of Figure 6 illustrate that individual bargaining is not a symmetric Nash equilibrium under European entry cost competition level of $\sigma_{E U, I}=9.7$. The upper right panel shows that a deviation to collective bargaining would be profitable in wage terms. The lower right panel shows that workers will indeed find it optimal to deviate. That is, employment losses due to the transition from individual to collective bargaining are small enough so that their negative impact on expected utility is outweighed by the utility gains due to wage increases for the retained workers. Hence, even when workers take into account that a deviation may lead to job losses, they find it profitable in expected utility terms to deviate to collective bargaining. As a result, individual bargaining cannot be a Nash equilib-

\footnotetext{
${ }^{21}$ The reason that the cutoff competition levels differ is that the deviation is considered assuming that all other firms stick to the respective equilibria. Hence, when checking the wage criterion for collective bargaining, the appropriate value of labor market tightness $\theta$ is that which results when all firms in the economy engage in collective bargaining. Similarly, the appropriate value of $\theta$ when checking for the optimality of deviations from a symmetric IB equilibrium is $\theta_{I}$.
} 
rium under high European entry costs.

To summarize: Under high continental European entry costs, collective bargaining emerges as the unique symmetric Nash equilibrium. Under low US entry costs, however, both individual and collective bargaining are symmetric Nash equilibria.

\subsection{Policy Experiment II}

We now use the balanced budget version of the model to now run a second policy experiment, whose goal is to gauge the ability of product market institutions in accounting for the US-continental Europe unemployment differential. In particular, differing product market institutions are represented as differing entry cost regimes $\left\{d_{\text {Euro }}, f_{\text {Euro }}\right\}$ and $\left\{d_{U S}, f_{U S}\right\} .{ }^{22}$ For each entry cost regime, we choose that bargaining regime which can be supported as a symmetric Nash equilibrium. Under continental European entry costs, collective bargaining turns out to be the unique symmetric Nash equilibrium, as is illustrated in Figure 6. Under lower US entry costs, individual bargaining is a symmetric Nash equilibrium. Since only $10.3 \%$ of US private sector workers were covered by a collective bargaining agreement in 1998, we choose individual bargaining as the relevant bargaining institution for the US. Hence, to assess the impact of product market reform, we measure the difference in unemployment between the high European entry cost and collective bargaining long run equilibrium on the one hand, and the low American entry cost and individual bargaining long run equilibrium on the other.

\subsubsection{Baseline Results}

The results of our policy experiment for the baseline calibration are shown in Table C. The long-run equilibrium for the US economy is shown in the first column, while the second column represents the continental European long-run equilibrium. The average markup of $14.7 \%$ in the European collective bargaining economy is roughly consistent with the average markups in the range 15-25\% for European economies reported in Martins, et. al. (1996).

\footnotetext{
${ }^{22}$ Following Fonseca, et. al. (2001) and Pissarides (2001), we use the regulatory delay index based on the Logotech/OECD data, together with Djankov, et. al. (2002)'s cost data. All entry cost data is reported in Table 2.
} 
The model was calibrated to allow long-run equilibrium unemployment in the US entry cost individual bargaining case to equal average US unemployment in the 90 's of $5.5 \%$. When entry costs are increased to their continental European levels, collective bargaining becomes relevant, and unemployment increases quite substantially, to $8.9 \%$ in the baseline calibration, almost reaching the average continental European unemployment level in the 90 's of $9.5 \%$. In the model economy, product market regulation accounts for about $85 \%$ of the US-European unemployment differential in the 90's, indicating that product market regulation could indeed be an important factor in accounting for the divergent performance of US and European labor markets. At the same time, our model generates real wages which are greater in the more competitive US economy by $5.6 \%$. The reason is that although individual bargaining grants workers a smaller bargaining surplus, these losses are outweighed by the gains to reservation utility due to greater probability of finding a job when unemployed in the US economy.

Next we check robustness of our results to key parameter choices, and find that increasing the replacement rate or decreasing the worker's matching rate would lead to a smaller US-European unemployment differential.

\subsubsection{Robustness}

In order to check the robustness of our results, we vary key calibration targets and parameter choices. We find that our results change only slightly when we vary the target job-finding and job-filling rates $\lambda_{w}$ and $\lambda_{f}$. We set the job-finding rate to match two alternative targets: The mean US unemployment duration in the 90's of 3.8 months and the median US unemployment duration over the same period of 1.7 months. Varying the target for $\lambda_{w}$ in this way has only minor effects on our results, while varying the job-filling rate $\lambda_{f}$ widely has negligible impact, as shown in Tables 6 and 7 respectively.

Our results are somewhat more sensitive to the choices of replacement rate target and firm exit probability. Increasing the replacement rate target to $50 \%$ results in a somewhat higher European entry cost-collective bargaining unemployment rate of $11.5 \%$, leading to a US-European unemployment gap of $6.0 \%$ as compared to $4.0 \%$ in the data. Decreasing the replacement rate target to a counterfactually 
low $10 \%$ leads to a smaller but still substantial US-European unemployment differential of $2.0 \%$, as shown in 8 . Hence, even when the replacement rate is counterfactually low, product market regulation can still account for about half the difference in US and continental European unemployment rates.

Varying the firm exit rate also has a moderate impact on the unemployment differential. Increasing the exit rate to $1.0 \%$ monthly ( about $11 \%$ annually) leads to a European-collective bargaining unemployment rate of $10.3 \%$, while decreasing $\delta$ to $0.6 \%$ (an annual exit rate of $7 \%$ ) reduces the European-collective bargaining unemployment rate in the model to $7.5 \%$. The reason is that increasing the firm exit rate increases the rate at which firms discount profits. This increases the rate at which entry costs must be amortized, shifting the entry cost curve upwards, and leading to lower levels of long-run equilibrium competition for given entry costs.

The one parameter choice to which our results are quite sensitive is that of the bargaining power and matching elasticity, as can be seen from Table 10. We continue to impose the Hosios condition, restricting our choices so that $\eta=\beta .^{23}$ Recently, Shimer (2005) has estimated US matching elasticity to be about 0.72 . Increasing matching elasticity and bargaining power to Shimer (2005)'s preferred values causes collective bargaining-high entry cost unemployment rates to sky-rocket to $19.4 \%$. However, matching elasticity to 0.4 , the lower bound of the range of matching elasticities reported by Petrongolo and Pissarides (2001) causes the highentry cost and collective bargaining unemployment rate to drop to $7.1 \%$. This still allows product market regulation to account for about $40 \%$ of the US-European unemployment differential.

\section{Transition Dynamics}

Finally, we consider the dynamics of product market deregulation. We model deregulation as a decrease in entry costs facing firms. By the analysis presented in the previous sections, a decrease in entry costs leads to an increase in competition.

We propose the following timing for firm entry. In our model, a measure $\delta$ of

\footnotetext{
${ }^{23}$ In Ebell and Haefke (2006), we show that the Hosios condition is necessary but not sufficient for efficiency under imperfect competition and individual bargaining.
} 
firms exits the market each period, and is replaced by a measure $\delta$ of new entrants. In their pre-entry period, the firm pays the entry cost, chooses a bargaining regime and posts enough vacancies to hire the steady-state employment level under that regime. Then, once the workers are hired they may freely choose to form a collective bargaining coalition, or to dissolve one.

In our quantitative experiments, firms' profits are always greater under individual bargaining ${ }^{24}$, so that firms will initially choose individual bargaining. If individual bargaining is stable, that is, if either individual bargaining is the symmetric Nash equilibrium or if individual and collective bargaining coexist at the current $(\sigma, \mu)$ levels, then IB will go on to be the steady bargaining institution of the firm. If, however, individual bargaining is not stable, then workers will choose to form a collective bargaining coalition. ${ }^{25}$ In our calibrated model, this will only be the case when the degree of monopoly power is sufficiently high.

We focus on the case in which the increase in competition moves the economy out of the high-monopoly power region in which collective bargaining is the unique Nash equilibrium to the high-competition region in which any share $(1-\mu)$ of individual bargaining firms can coexist with the share $\mu$ of collective bargaining firms. In this case, a product market deregulation would bring about a gradual decline in the share of collective bargaining firms. In particular, each period a fraction $\delta$ of existing firms would exist, a fraction $\mu$ of which would be collective bargaining firms. All exiting firms would be replaced by a flow $\delta$ of new individual bargaining firms. Hence, we would expect the share of individual bargaining firms to increase at the rate $\delta \mu$, where $\mu$ is decreasing over time. As a result, unemployment would decrease gradually over time, as more low-employment collective bargaining firms are replaced by higher-employment individual bargaining firms.

\footnotetext{
${ }^{24}$ It is not possible to establish this analytically for all parameter constellations. We did not, however, succeed in generating any example in which collective bargaining profits exceeded those under individual bargaining.

${ }^{25}$ Note that although workers are ultimately the owners of the firms, their holdings are assumed to be fully diversified, so that they neglect the impact of their bargaining decisions on their own firm's profits.
} 


\section{Conclusions}

The main contributions of this paper have been threefold. First, we have shown that the choice of bargaining regime is crucial for the effect of product market competition on unemployment rates, being substantial under collective bargaining and negligible under individual bargaining. Since the choice of bargaining institution is so important, we endogenize it. We find that the bargaining regime which emerges endogenously depends crucially on the degree of product market competition. When product market competition is low, collective bargaining is stable, while individual bargaining is also a stable institution under high degrees of product market competition. This allows us to link product market competition and collective bargaining coverage rates and to characterize the transition dynamics of a product market deregulation. Our results suggest that the strong decline in collective bargaining coverage and unionization in the US and UK over the last two decades might have been a direct consequence of the Reagan/Thatcher product market reforms of the early 80 's. Finally, we calibrate the model to US data, in order to assess the quantitative impact of product market regulation on equilibrium unemployment rates. In the calibrated version of the model, low US regulation leads to very high degrees of product market competition and individual bargaining can be supported as a bargaining institution. High EU regulation leads to low degrees of product market competition, and collective bargaining emerges as the endogenous bargaining institution. We find that moving from the low US regulation-individual bargaining economy to the high EU regulation-collective bargaining economy leads to a substantial increase in equilibrium unemployment rates from $5.5 \%$ to $8.9 \%$ in the model economy. This accounts for more than four-fifths of the total average unemployment differential of about $4.0 \%$ points between the US and continental Europe in the 90s. 


\section{References}

[1] Abowd, J.A. and L. Allain (1996), "Compensation Structure and Product Market Competition," Annales d'Economie et de Statistique, (41/42), 207-218.

[2] Bertrand, M. and F. Kramarz (2002), “Does Entry Regulation Hinder Job Creation? Evidence from the French Retail Industry," Quarterly Journal of Economics 117, 1369-1413.

[3] Binmore, K., A. Rubinstein and A. Wolinsky (1986), "The Nash Bargaining Solution in Economic Modeling," RAND Journal of Economics 17, 176-188.

[4] Blanchard, O. and F. Giavazzi (2003), "Marcoeconomic Effects of Regulation and Deregulation in Goods and Labor Markets," Quarterly Journal of Economics $118,879-907$.

[5] Boeri, T., G. Nicoletti and S. Scarpetta (2000), "Regulation and Labour Market Performance," CEPR Discussion paper 2420.

[6] Cahuc, P. and E. Wasmer (2001), "Does Intrafirm Bargaining Matter in the Large Firm's Matching Model?" Macroeconomic Dynamics 5, 178-89.

[7] Cahuc, P., C. Gianella, D. Goux, and A. Zylberberg (2002), “Equalizing Wage Differences and Bargaining Power: Evidence From a Panel of French Firms," CEPR Discussion Paper 3510.

[8] Cahuc, P., F. Marque, and E. Wasmer (2004), “Intrafirm Wage Bargaining in Matching Models: Macroeconomic Implications and Resolution Methods with Multiple Labor Inputs" mimeo , 2004.

[9] Delacroix, A. (2006), “A Multisectoral Matching Model of Unions, ” Journal of Monetary Economics, forthcoming.

[10] Djankov, S., R. La Porta, F. Lopez-de-Silanes and A. Shleifer (2002), “The Regulation of Entry," Quarterly Journal of Economics 117, 1-37.

[11] Ebell, M. and C. Haefke, " Product Market Deregulation and Labor Market Outcomes, " IZA Working Paper 957, 12/2003. 
[12] Ebell, M. and C. Haefke, " Product Market Deregulation and the U.S. Employment Miracle, "IZA Working Paper 1946, 1/2006.

[13] Fonseca, R., Lopez-Garcia, P. and C. Pissarides (2001), "Entrepreneurship, Start-up Costs and Unemployment," European Economic Review 45, 692-705.

[14] Fujita, S. and G. Ramey, “ The Dynamic Beveridge Curve," mimeo, UCSD, $11 / 2005$.

[15] Galí, J., (1995), “ Non-Walrasian Unemployment Fluctuations,, NBER Working Paper 5337.

[16] Galí, J., and F. Zilibotti, (1995), “ Endogenous Growth and Poverty Traps in a Cournotian Model, " Annales d'Economie et Statistique, 37/38, 197-214.

[17] den Haan, W.J., G. Ramey, and J. Watson (2000), “Job Destruction and Propagation of Shocks," American Economic Review 90, 482-498.

[18] Hamermesh, D.S. and G.A. Pfann, (1996), “Adjustment Costs in Factor Demand," Journal of Economic Literature 34, 1264-1292.

[19] Hirsch, Barry T. and David A. Macpherson, "Union Membership and Coverage Database from the Current Population Survey: Note," Industrial and Labor Relations Review, Vol. 56, No. 2, January 2003, pp. 349-54.

[20] Hosios, A.J., "On the Efficiency of Matching and Related Models of Search and Unemployment," Review of Economic Studies, 1990, 57, 279-298.

[21] Machin, Stephen (2000), "Union Decline in Britain," mimeo, University College London.

[22] Martins, Joaquim Oliveira, Stefano Scarpetta and Dirk Pilat (1996), "Mark-Up Ratios in Manufacturing Industries: Estimates for 14 Countries," OECD Economics Department Working Paper Nr. 162.

[23] Mata, Jose and Pedro Portugal (1994), "Life duration of new firms," Journal of Industrial Economics, 44, 227-245.

[24] Nickell, S. (1999), "Product Markets and Labour Markets," Labor Economics 6, $1-20$. 
[25] OECD Employment Outlook, June 2001.

[26] Petrongolo, B. and Pissarides, C.A., (2001), "Looking into the Black Box: A Survey of the Matching Function," Journal of Economic Literature 39, 716-741.

[27] Pissarides, C.A. (2001), "Company Start-Up Costs and Employment," CEP Discussion Paper 520.

[28] Schiantarelli, F. (2005), "Product Market Regulation and Macroeconomic Performance: A Review of Cross Country Evidence," IZA Working paper 1791.

[29] Shimer, R. (2005), "The Cyclical Behavior of Equilibrium Unemployment and Vacancies," American Economic Review 95, 25-49.

[30] Smith, E. (1999), "Search, Concave Production and Optimal Firm Size," Review of Economic Dynamics 2, 456-471.

[31] Spector, D. (2004), "Competition and the Capital-Labor Conflict," European Economic Review, 48, 25-38.

[32] Stole, L. and J. Zwiebel (1996), "Intra-firm Bargaining under Non-Binding Contracts," Review of Economic Studies 63, 375-410.

[33] Stole, L. and J. Zwiebel (1996a), “Organizational Design and Technology Choice under Intrafirm Bargaining," American Economic Review 86, 195-222.

[34] Wagner, J. (1994), “The Post-Entry Performance of New Small Firms in German Manufacturing Industries," Journal of Industrial Economics, 42(2), 141-54.

[35] Yashiv, E. (2001), “Wage Bargaining, the Value of Unemployment, and the Labor Share of Income," Tel Aviv University, mimeo. 


\section{Appendix A Reservation Wages for Arbitrary $\mu$}

For arbitrary $\mu$, we have

$$
\begin{aligned}
\frac{w_{I}\left(\theta_{\mu}\right)}{P} & =\frac{r V^{U}\left(\theta_{\mu}\right)}{P}+\frac{\beta}{1-\beta} \frac{\Phi_{V}}{q\left(\theta_{\mu}\right)}\left(\frac{r+\chi}{1-\delta}\right) \\
\frac{w_{C}\left(\theta_{\mu}\right)}{P} & =\left[1+\frac{\beta}{\sigma-1}\right] \frac{r V^{U}\left(\theta_{\mu}\right)}{P}+\frac{\beta}{\sigma-1} \frac{\Phi_{V} \widetilde{\chi}}{q(\theta)} \\
\frac{r V^{U}\left(\theta_{\mu}\right)}{P} & =\frac{r+\chi}{r+\chi+\theta_{\mu} q\left(\theta_{\mu}\right)} b+\frac{\theta_{\mu} q\left(\theta_{\mu}\right)}{r+\chi+\theta_{\mu} q\left(\theta_{\mu}\right)}\left\{\mu \frac{w_{C}\left(\theta_{\mu}\right)}{P}+(1-\mu) \frac{w_{I}\left(\theta_{\mu}\right)}{P}\right\}
\end{aligned}
$$

This gives us three equations in the three unknowns $w_{C}\left(\theta_{\mu}\right), w_{I}\left(\theta_{\mu}\right), r V^{U}\left(\theta_{\mu}\right)$. First, solve for the reservation utility:

$$
\begin{aligned}
\frac{r V^{U}\left(\theta_{\mu}\right)}{P}= & \frac{(r+\chi)(\sigma-1)}{(r+\chi)(\sigma-1)-\beta \mu \theta_{\mu} q\left(\theta_{\mu}\right)} b \\
& +\frac{\beta \Phi_{V} \theta_{\mu}}{(r+\chi)(\sigma-1)-\beta \mu \theta_{\mu} q\left(\theta_{\mu}\right)}\left[\mu(\widetilde{\chi}-r-\delta)+\frac{(1-\mu)(\sigma-1)}{1-\beta}\left(\frac{r+\chi}{1-\delta}\right)\right]
\end{aligned}
$$

which corresponds to equation (27) in the main text. When $\mu=0$, the reservation wage reduces to:

$$
\frac{r V^{U}\left(\theta_{I}\right)}{P}=b+\frac{\beta}{1-\beta}\left(\frac{\Phi_{V}}{1-\delta}\right) \theta_{I} .
$$

For $\mu=1$, the reservation wage reduces to:

$$
\frac{r V^{U}\left(\theta_{C}\right)}{P}=\frac{(r+\chi)(\sigma-1)}{(r+\chi)(\sigma-1)-\beta \theta_{C} q\left(\theta_{C}\right)} b-\frac{\beta \Phi_{V} \theta_{C}}{(r+\chi)(\sigma-1)-\beta \theta_{C} q\left(\theta_{C}\right)}(r+\delta-\tilde{\chi}) .
$$

\section{Appendix B Proofs}

\section{B.1 Proof of Lemma 3}

(i) By Lemma 1, if $w_{C}\left(\theta_{C}\right) \geq w_{I}\left(\theta_{C}\right)$, then collective bargaining is a symmetric Nash equilibrium. By equations (18), (22) and (26), we have that $w_{C}\left(\theta_{C}\right) \geq w_{I}\left(\theta_{C}\right)$ if and only if:

$$
\frac{\beta(r+\chi)}{(r+\chi)(\sigma-1)-\beta \theta_{C} q\left(\theta_{C}\right)}\left(b+\frac{\Phi_{V}}{q\left(\theta_{C}\right)} \tilde{\chi}\right) \geq \frac{\beta}{1-\beta} \frac{\Phi_{V}}{q\left(\theta_{C}\right)}\left(\frac{r+\chi}{1-\delta}\right)
$$

which reduces to the condition that:

$$
1+\frac{(1-\beta)(1-\delta)}{r+\chi}\left[b \frac{q\left(\theta_{C}\right)}{\Phi_{V}}+\widetilde{\chi}\right]+\beta \frac{\theta_{C} q\left(\theta_{C}\right)}{r+\chi} \geq \sigma
$$

(ii) By Lemma 1, if $w_{I}\left(\theta_{I}\right) \geq w_{C}\left(\theta_{I}\right)$, then collective bargaining is a symmetric Nash equilibrium. By equations (18), (22) and (26), we have that $w_{I}\left(\theta_{I}\right) \geq w_{C}\left(\theta_{I}\right)$ if and only if:

$$
\frac{\beta(r+\chi)}{(r+\chi)(\sigma-1)-\beta \theta_{I} q\left(\theta_{I}\right)}\left(b+\frac{\Phi_{V} \tilde{\chi}}{q\left(\theta_{I}\right)}\right) \leq \frac{\beta}{1-\beta} \frac{\Phi_{V}}{q\left(\theta_{I}\right)}\left(\frac{r+\chi}{1-\delta}\right)
$$


which reduces to the condition that:

$$
1+\frac{(1-\beta)(1-\delta)}{r+\chi}\left[b \frac{q\left(\theta_{I}\right)}{\Phi_{V}}+\tilde{\chi}\right]+\beta \frac{\theta_{I} q\left(\theta_{I}\right)}{r+\chi} \leq \sigma
$$

\section{B.2 Proof of Proposition 1}

The proof proceeds in three steps. First, we show that individual bargaining is a Nash equilibrium under perfect competition. Next, we show that collective bargaining is also a Nash equilibrium in the perfect competition limit. By continuity, this implies that 'mixed strategy' equilibria exists for any $\mu \in(0,1)$.

(i) By Lemma 1, to show that individual bargaining is a Nash equilibrium under perfect competition, it is sufficient to show that

$$
\lim _{\sigma \rightarrow \infty} w_{I}\left(\theta_{I}\right) \geq \lim _{\sigma \rightarrow \infty} w_{C}\left(\theta_{I}\right)
$$

First, from equations (26) and (22) it is straightforward to see that $\lim _{\sigma \rightarrow \infty} w_{C}\left(\theta_{I}\right)=b$. From equations (18) and (25), however, the individual bargaining wage converges to

$$
\lim _{\sigma \rightarrow \infty} w_{I}\left(\theta_{I}\right)=b+\frac{\beta}{1-\beta} \frac{\Phi_{V}}{q\left(\bar{\theta}_{I}\right)}\left[\frac{r+\chi+\bar{\theta}_{I} q\left(\bar{\theta}_{I}\right)}{1-\delta}\right]
$$

where $\bar{\theta}_{I}>0$ is the (finite) limit of $\theta_{I}(\sigma)$ as $\sigma \rightarrow \infty$. It is easy to see that the second term of $\lim _{\sigma \rightarrow \infty} w_{I}\left(\theta_{I}\right)$ is strictly positive, so that indeed. $\lim _{\sigma \rightarrow \infty} w_{I}\left(\theta_{I}\right) \geq \lim _{\sigma \rightarrow \infty} w_{C}\left(\theta_{I}\right)$.

(ii) It follows from part (i) that collective bargaining is not a Nash equilibrium by the wage condition. It could however be the case that workers in collective bargaining firms do not wish to deviate to individual bargaining by the employment criterium (because the job losses are too large). It turns out that workers are just indifferent between deviating to the higherwage IB regime and remaining with $C B$. To see this, first note that the employment condition for a $C B$ symmetric equilibrium reduces to:

$$
H_{C}\left[V_{C}^{E}-V^{U}\right] \geq H_{I}\left[V_{I}^{E}-V^{U}\right]
$$

Substituting in from equations (1), (2), (18), (22), (20) and (24) yields the following condition for collective bargaining to be a symmetric Nash equilibrium:

$$
\begin{aligned}
& \left(\frac{\sigma-\beta}{\sigma}\right)^{\sigma}\left[w_{C}\left(1-\tau_{I}\right)-r V^{U}\right] \\
\geq & (\underbrace{\frac{\frac{1+\tau_{P}}{1-\tau_{I}} \frac{r V^{U}}{P}+\frac{\Phi_{V} P}{q\left(\theta_{\mu}\right)} \widetilde{\chi}}{\frac{1+\tau_{P}}{1-\tau_{I}} \frac{r V^{U}}{P}+\frac{1}{1-\beta} \frac{\Phi_{V}}{q\left(\theta_{\mu}\right)} \frac{r+\chi}{1-\delta}}}_{<1})^{\sigma} \underbrace{\left[w_{I}\left(1-\tau_{I}\right)-r V^{U}\right]}_{>0}
\end{aligned}
$$


Taking limits of both sides as $\sigma \rightarrow \infty$ leads to the inequality being binding (holding as an equality). To see this, first note that the limit of the LHS is zero because collective bargaining surplus converges to zero in the perfect competition limit and because $\left(\frac{\sigma-\beta}{\sigma}\right)^{\sigma}$ is finite. The RHS also converges to zero, because the individual bargaining surplus remains finite as $\sigma \rightarrow \infty$, while the term in brackets is less than one and hence converges to zero as the exponent $\sigma$ approaches infinity. This establishes that collective bargaining is also a symmetric Nash equilibrium in the perfect competition limit.

(iii) By parts (i) and (ii) and continuity, this implies that 'mixed strategy' equilibria exists for any $\mu \in(0,1)$ in the perfect competition limit.

\section{B.3 Proof of Proposition 2}

By Lemma 1, to establish that collective bargaining is a symmetric Nash equilibrium in the imperfect competition limit, it is sufficient to show that:

$$
\lim _{\theta_{C} \rightarrow 0} w_{C}\left(\theta_{C}, \sigma_{\min }\right) \geq \lim _{\theta_{C} \rightarrow 0} w_{I}\left(\theta_{C}, \sigma_{\min }\right)
$$

From equations (22) and (26), it is easy to see that:

$$
\begin{aligned}
& \lim _{\theta_{C} \rightarrow 0} w_{C}\left(\theta_{C}, \sigma_{\min }\right) \\
= & \lim _{\theta_{C} \rightarrow 0}\left[\frac{(r+\chi)\left(\sigma_{\min }-1\right)}{(r+\chi)\left(\sigma_{\min }-1\right)-\beta \theta_{C}\left(\theta_{C}\right)} b+\frac{\beta \theta_{C} q\left(\theta_{C}\right)}{(r+\chi)\left(\sigma_{\min }-1\right)-\beta \theta_{C} q\left(\theta_{C}\right)} \frac{\Phi_{V}}{q\left(\theta_{C}\right)} \tilde{\chi}\right] . \\
& {\left[1+\frac{\beta}{\sigma_{\min }-1}\right]+\frac{\beta}{\sigma_{\min }-1} \frac{\Phi_{V}}{q\left(\theta_{C}\right)} \tilde{\chi} } \\
= & b\left[1+\frac{\beta}{\sigma_{\min }-1}\right]
\end{aligned}
$$

From equations (15) and (26), one can also establish that:

$$
\begin{aligned}
& \lim _{\theta_{C} \rightarrow 0} w_{I}\left(\theta_{C}, \sigma_{\min }\right) \\
= & \lim _{\theta_{C} \rightarrow 0} \frac{(r+\chi)\left(\sigma_{\min }-1\right)}{(r+\chi)\left(\sigma_{\min }-1\right)-\beta \theta_{C} q\left(\theta_{C}\right)} b \\
& +\frac{\beta \theta_{C} q\left(\theta_{C}\right)}{(r+\chi)\left(\sigma_{\min }-1\right)-\beta \theta_{C} q\left(\theta_{C}\right)} \frac{\Phi_{V}}{q\left(\theta_{C}\right)} \tilde{\chi}+\frac{\beta}{1-\beta} \frac{\Phi_{V}}{q\left(\theta_{\mu}\right)}\left(\frac{r+\chi}{1-\delta}\right) \\
= & b
\end{aligned}
$$

The fact that $\sigma_{\min }>1$ confirms that indeed

$\lim _{\theta_{C} \rightarrow 0} w_{C}\left(\theta_{C}, \sigma_{\min }\right)>\lim _{\theta_{C} \rightarrow 0} w_{I}\left(\theta_{C}, \sigma_{\min }\right)$. 


\section{B.4 Proof of Proposition 3}

The wage condition of Lemma 1 guarantees the existence of a collective bargaining symmetric Nash equilibrium for values of $\theta_{C}$ such that:

$$
(1-\delta)(1-\beta)\left[b+\frac{\Phi_{V}}{q_{C}} \widetilde{\chi}\right] \geq(r+\chi) \frac{\Phi_{V}}{q_{C}} \sigma-(r+\chi) \frac{\Phi_{V}}{q_{C}}-\beta \Phi_{V} \theta_{C}
$$

where $\sigma$ and $\theta_{C}$ are related by equation (33) as

$$
\sigma=A \frac{r+\chi+\beta \theta_{C} q\left(\theta_{C}\right)}{(r+\chi)\left[A-b-\frac{\Phi_{V}}{q_{C}} \tilde{\chi}\right]}
$$

Combining equations (45) and (46) yields an implicit condition on $\theta_{C}$ which guarantees existence of a collective bargaining symmetric Nash equilibrium:

$$
(1-\delta)(1-\beta) \geq(r+\chi) \frac{\Phi_{V}}{q_{C}}+\beta \Phi_{V} \theta_{C}
$$

When $q\left(\theta_{C}\right)=s \theta_{C}^{-\frac{1}{2}}$, condition (47) reduces to a quadratic equation in $\sqrt{\theta_{C}}$ :

$$
\beta \Phi_{V} \theta_{C}+(r+\chi) \frac{\Phi_{V}}{s} \sqrt{\theta_{C}}-(1-\delta)(1-\beta) \leq 0
$$

This quadratic equation has one positive root, and hence a unique non-complex value of labor market tightness at which the collective and individual bargaining surpluses are equal. The positive root satisfies:

$$
\sqrt{\theta_{C}}=\frac{-(r+\chi) \frac{\Phi_{V}}{s}+\sqrt{\left((r+\chi) \frac{\Phi_{V}}{s}\right)^{2}+4 \beta \Phi_{V}(1-\delta)(1-\beta)}}{2 \beta \Phi_{V}}
$$

so that the critical value $\widetilde{\theta}_{C}$ such that for all $\theta_{C} \leq \widetilde{\theta}_{C}$, collective bargaining is a symmetric Nash equilibrium satisfies:

$$
\widetilde{\theta}_{C}=\left(\frac{-(r+\chi) \frac{\Phi_{V}}{s}+\sqrt{\left((r+\chi) \frac{\Phi_{V}}{s}\right)^{2}+4 \beta \Phi_{V}(1-\delta)(1-\beta)}}{2 \beta \Phi_{V}}\right)^{2}
$$

Since $\theta_{C}$ is a monotonically increasing function of the degree of competition $\sigma$ (by $(46))$, there also exists a critical value of competition $\widetilde{\sigma}_{C} \equiv \sigma\left(\widetilde{\theta}_{C}\right)$ such that for all $\sigma \leq \widetilde{\sigma}_{C}$, there exists a symmetric collective bargaining Nash equilibrium. 
Appendix C Tables 
Table 1: Entry Costs

\begin{tabular}{l|ccc|cccc}
\hline \multicolumn{1}{c|}{ Dataset } & \multicolumn{3}{c|}{ OECD } & \multicolumn{3}{c}{ Djankov, et. al. } \\
\hline \multicolumn{1}{c}{ Country } & Days & Procedures & Index & Days & Procedures & Fees \\
\hline Austria & 40 & 10 & 35.2 & 37 & 9 & $27.3 \%$ \\
Belgium & 30 & 7 & 25.6 & 33 & 8 & $10.0 \%$ \\
France & 30 & 16 & 39.3 & 53 & 15 & $14.3 \%$ \\
Germany & 80 & 10 & 55.2 & 42 & 10 & $15.7 \%$ \\
Greece & 32.5 & 28 & 58.7 & 36 & 15 & $58.6 \%$ \\
Italy & 50 & 25 & 62.9 & 62 & 16 & $20.0 \%$ \\
Netherlands & 60 & 9 & 43.7 & 31 & 8 & $18.4 \%$ \\
Portugal & 40 & 10 & 35.2 & 76 & 12 & $18.4 \%$ \\
Spain & 117.5 & 17 & 84.5 & 82 & 11 & $17.3 \%$ \\
Euro Average & $\mathbf{6 2 . 2}$ & - & $\mathbf{5 4 . 7}$ & $\mathbf{5 1 . 9}$ & - & $18.4 \%$ \\
United States & $\mathbf{7 . 5}$ & $\mathbf{3 . 5}$ & $\mathbf{8 . 6}$ & & 4 & $0.5 \%$ \\
\hline
\end{tabular}

The 'Days' column gives the number of business days necessary to start a new firm, while the 'Procedures' column gives the number of entry procedures which new firms must complete. The 'Index' column combines the 'Days' and 'Procedures' measures as (days + procedures/(ave procedures/day))/2, so that the indexes' units are days. The first two columns draw on 1997 data from Logotech S.A., as reported by the OECD [Fostering Entrepreneurship] and by Fonseca,et.al. (2001). The index is taken from Fonseca, et. al. (2001). The fourth and fifth column present the respective days and procedures measures reported by Djankov, et.al. (2002) for 1997. The sixth column gives Djankov, et.al. (2002)'s measure for fees required for entry, as a percentage of per capita GDP. 
Table 2: Calibration to U.S. data

\begin{tabular}{crll}
\hline & & Interpretation & Source \\
\hline$\beta$ & 0.50 & Worker bargaining power & standard \\
$\eta$ & 0.50 & Elasticity of the matching function & standard \\
$A$ & 1 & Average level of labor productivity & normalization \\
$r$ & 0.0033 & $4.0 \%$ Annual interest rate & standard \\
$b$ & 0.28 & Real unemployment benefits, US & $30 \%$ replacement rate \\
$\delta$ & 0.008 & Probability of firm exit & micro-data \\
$\lambda_{w}$ & 0.45 & Job finding rate & Shimer (2005) \\
$\lambda_{f}$ & $\frac{1}{4.2}$ & Job filling rate & Den Haan et. al. (2000) \\
$\theta_{I}$ & 1.89 & Labor market tightness & $\theta=\frac{\lambda_{w}}{\lambda_{f}}$ \\
$s$ & 0.33 & Scaling parameter of matching function & $s=\frac{\lambda_{w}}{\theta^{1-\eta}}$ \\
$\Phi_{V}$ & 0.33 & Real vacancy posting cost & $u=5.5 \%$ \\
$\chi$ & 0.026 & Total separation rate & $u=\frac{\chi}{\chi+\lambda_{w}}$ \\
\hline
\end{tabular}

Table 3: Policy Experiment I with Individual Bargaining

\begin{tabular}{|l|cc|}
\hline & US $\Phi_{E}$ & EU $\Phi_{E}$ \\
\hline Unemployment $u\left(\sigma^{*}\right)$ & $5.5 \%$ & $5.6 \%$ \\
Unemployment duration $\frac{1}{\theta q(\theta)}$ & 2.2 & 2.3 \\
Vacancy duration $\frac{1}{q(\theta)}$ & 4.2 & 4.1 \\
Replacement rate & 0.30 & 0.30 \\
Matching elasticity $\eta=\beta$ & 0.50 & 0.50 \\
\hline Real unemployment benefit $b$ & 0.28 & 0.27 \\
Total separation rate $\chi$ & 0.026 & 0.026 \\
Labor market tightness $\theta\left(\sigma^{*}\right)$ & 1.89 & 1.79 \\
\hline Equ. demand elasticity $\sigma^{*}$ & 96.2 & 9.7 \\
Real net wage $w\left(1-\tau_{l}\right)$ & 0.94 & 0.89 \\
Res utility $r V^{U}$ & 0.90 & 0.85 \\
Worker's match surplus & 0.04 & 0.04 \\
Profit per firm $\pi$ & 0.020 & 0.066 \\
Markup & $0.5 \%$ & $5.7 \%$ \\
Tax rates $\tau_{l}=\tau_{P}$ & $0.9 \%$ & $0.9 \%$ \\
Vacancy costs $\Phi_{V}$ & 0.33 & 0.33 \\
\hline
\end{tabular}


Table 4: Policy Experiment I with Collective Bargaining

\begin{tabular}{|l|cc|}
\hline & EU $\Phi_{E}$ & US $\Phi_{E}$ \\
\hline Unemployment $u\left(\sigma^{*}\right)$ & $8.9 \%$ & $3.8 \%$ \\
Unemployment duration $\frac{1}{\theta q(\theta)}$ & 3.7 & 1.5 \\
Vacancy duration $\frac{1}{q(\theta)}$ & 2.5 & 6.1 \\
Replacement rate & 0.30 & 0.30 \\
Matching elasticity $\eta=\beta$ & 0.50 & 0.50 \\
\hline Real unemployment benefit $b$ & 0.27 & 0.28 \\
Total separation rate $\chi$ & 0.026 & 0.026 \\
Labor market tightness $\theta\left(\sigma^{*}\right)$ & 0.67 & 4.03 \\
\hline Equ. demand elasticity $\sigma^{*}$ & 7.8 & 17.8 \\
Real net wage $w\left(1-\tau_{l}\right)$ & 0.89 & 0.92 \\
Res utility $r V^{U}$ & 0.83 & 0.90 \\
Worker's match surplus & 0.06 & 0.02 \\
Profit per firm $\pi$ & 0.058 & 0.027 \\
Markup & $14.7 \%$ & $5.6 \%$ \\
Tax rates $\tau_{l}=\tau_{P}$ & $1.4 \%$ & $0.6 \%$ \\
Vacancy costs $\Phi_{V}$ & 0.33 & 0.33 \\
\hline
\end{tabular}


Table 5: Policy Experiment II: Endogenous Bargaining

\begin{tabular}{|l|cc|}
\hline & US $\Phi_{E}$ & Euro $\Phi_{E}$ \\
\hline Unemployment $u\left(\sigma^{*}\right)$ & $5.5 \%$ & $8.9 \%$ \\
Unemployment duration $\frac{1}{\theta q(\theta)}$ & 2.2 & 3.7 \\
Vacancy duration $\frac{1}{q(\theta)}$ & 4.2 & 2.5 \\
Replacement rate & 0.30 & 0.30 \\
Matching elasticity $\eta=\beta$ & 0.50 & 0.50 \\
\hline Real unemployment benefit $b$ & 0.28 & 0.27 \\
Total separation rate $\chi$ & 0.026 & 0.026 \\
Labor market tightness $\theta\left(\sigma^{*}\right)$ & 1.89 & 0.67 \\
\hline Equ. demand elasticity $\sigma^{*}$ & 96.2 & 7.8 \\
Real net wage $\frac{w}{P}\left(1-\tau_{I}\right)$ & 0.94 & 0.89 \\
Res. Utility $r V^{U}$ & 0.90 & 0.83 \\
Worker's Match Surplus & 0.04 & 0.06 \\
Profit per firm $\frac{\pi}{P}$ & 0.020 & 0.058 \\
Markup & $0.5 \%$ & $14.7 \%$ \\
Tax rates $\tau_{I}=\tau_{P}$ & $0.9 \%$ & $1.4 \%$ \\
Vacancy costs $\Phi_{V}$ & 0.33 & 0.33 \\
\hline
\end{tabular}

This table presents the equilibrium values for main variables of two economies. The first column gives results for the US economy under individual bargaining, while the second column gives results for the same economy, but with continental European entry costs and under collective bargaining. 
Table 6: Robustness to Choice of $\lambda_{w}$

\begin{tabular}{|l|cc|cc|}
\hline & $\lambda_{w}=\frac{1}{3.8}$ & & $\lambda_{w}=\frac{1}{1.7}$ & \\
\hline & US $\Phi_{E}$ & Euro $\Phi_{E}$ & US $\Phi_{E}$ & Euro $\Phi_{E}$ \\
\hline Unemployment $u\left(\sigma^{*}\right)$ & $5.5 \%$ & $9.1 \%$ & $5.5 \%$ & $8.8 \%$ \\
Unemployment duration $\frac{1}{\theta q(\theta)}$ & 3.8 & 6.6 & 1.7 & 2.9 \\
Vacancy duration $\frac{1}{q(\theta)}$ & 4.2 & 2.4 & 4.2 & 2.5 \\
Replacement rate & 0.30 & 0.30 & 0.30 & 0.30 \\
Matching elasticity $\eta=\beta$ & 0.50 & 0.50 & 0.50 & 0.50 \\
\hline Real unemployment benefit $b$ & 0.28 & 0.27 & 0.28 & 0.27 \\
Total separation rate $\chi$ & 0.015 & 0.015 & 0.034 & 0.034 \\
Labor market tightness $\theta\left(\sigma^{*}\right)$ & 1.10 & 0.37 & 2.47 & 0.89 \\
\hline Equ. demand elasticity $\sigma^{*}$ & 97.8 & 7.1 & 95.7 & 8.1 \\
Real net wage $\frac{w}{P}\left(1-\tau_{I}\right)$ & 0.93 & 0.89 & 0.94 & 0.90 \\
Res. Utility $r V^{U}$ & 0.89 & 0.83 & 0.90 & 0.84 \\
Worker's Match Surplus & 0.04 & 0.06 & 0.04 & 0.06 \\
Markup & $0.5 \%$ & $16.4 \%$ & $0.5 \%$ & $14.1 \%$ \\
Tax rates $\tau_{I}=\tau_{P}$ & $0.9 \%$ & $1.5 \%$ & $0.9 \%$ & $1.4 \%$ \\
Vacancy costs $\Phi_{V}$ & 0.56 & 0.56 & 0.25 & 0.25 \\
\hline
\end{tabular}

This table repeats the policy experiment first for the value $\lambda_{w}=\frac{1}{3.8}$ of the worker matching rate which matches mean US unemployment duration in the 90 's, as well as for a value $\lambda_{w}=\frac{1}{1.7}$ which matches median US unemployment duration over the same period. 
Table 7: Robustness to Choice of $\lambda_{f}$

\begin{tabular}{|l|cc|cc|}
\hline & $q(\theta)=\frac{1}{10}$ & & $q(\theta)=\frac{1}{2}$ & \\
\hline & US $\Phi_{E}$ & Euro $\Phi_{E}$ & US $\Phi_{E}$ & Euro $\Phi_{E}$ \\
\hline Unemployment $u\left(\sigma^{*}\right)$ & $5.5 \%$ & $8.9 \%$ & $5.5 \%$ & $8.9 \%$ \\
Unemployment duration $\frac{1}{\theta q(\theta)}$ & 2.2 & 3.8 & 2.2 & 3.8 \\
Vacancy duration $\frac{1}{q(\theta)}$ & 10.0 & 6.0 & 2.0 & 1.2 \\
Replacement rate & 0.30 & 0.30 & 0.30 & 0.30 \\
Matching elasticity $\eta=\beta$ & 0.50 & 0.50 & 0.50 & 0.50 \\
\hline Real unemployment benefit $b$ & 0.28 & 0.27 & 0.28 & 0.27 \\
Total separation rate $\chi$ & 0.026 & 0.026 & 0.026 & 0.026 \\
Labor market tightness $\theta\left(\sigma^{*}\right)$ & 4.50 & 1.59 & 0.90 & 0.32 \\
\hline Equ. demand elasticity $\sigma^{*}$ & 96.2 & 7.8 & 96.2 & 7.8 \\
Real net wage $\frac{w}{P}\left(1-\tau_{I}\right)$ & 0.94 & 0.89 & 0.94 & 0.89 \\
Res. Utility $r V^{U}$ & 0.90 & 0.83 & 0.90 & 0.83 \\
Worker's Match Surplus & 0.04 & 0.06 & 0.04 & 0.06 \\
Markup & $0.5 \%$ & $14.7 \%$ & $0.5 \%$ & $14.7 \%$ \\
Tax rates $\tau_{I}=\tau_{P}$ & $0.9 \%$ & $1.4 \%$ & $0.9 \%$ & $1.4 \%$ \\
Vacancy costs $\Phi_{V}$ & 0.14 & 0.14 & 0.69 & 0.69 \\
\hline
\end{tabular}

This table repeats the policy experiment first for alternative values of the firm's matching rate. 
Table 8: Robustness to Choice of Replacement Rate

\begin{tabular}{|l|cc|cc|}
\hline & $r r=0.10$ & & $r r=0.50$ & \\
\hline & US $\Phi_{E}$ & Euro $\Phi_{E}$ & US $\Phi_{E}$ & Euro $\Phi_{E}$ \\
\hline Unemployment $u\left(\sigma^{*}\right)$ & $5.5 \%$ & $7.5 \%$ & $5.5 \%$ & $11.5 \%$ \\
Unemployment duration $\frac{1}{\theta q(\theta)}$ & 2.2 & 3.1 & 2.2 & 4.9 \\
Vacancy duration $\frac{1}{q(\theta)}$ & 4.2 & 2.9 & 4.2 & 1.9 \\
Replacement rate & 0.10 & 0.10 & 0.50 & 0.50 \\
Matching elasticity $\eta=\beta$ & 0.50 & 0.50 & 0.50 & 0.50 \\
\hline Real unemployment benefit $b$ & 0.09 & 0.09 & 0.47 & 0.44 \\
Total separation rate $\chi$ & 0.026 & 0.026 & 0.026 & 0.026 \\
Labor market tightness $\theta\left(\sigma^{*}\right)$ & 1.89 & 0.96 & 1.89 & 0.38 \\
\hline Equ. demand elasticity $\sigma^{*}$ & 96.8 & 7.3 & 95.6 & 8.4 \\
Real net wage $\frac{w}{P}\left(1-\tau_{I}\right)$ & 0.94 & 0.90 & 0.94 & 0.87 \\
Res. Utility $r V^{U}$ & 0.89 & 0.83 & 0.91 & 0.82 \\
Worker's Match Surplus & 0.05 & 0.07 & 0.03 & 0.05 \\
Markup & $0.5 \%$ & $15.9 \%$ & $0.5 \%$ & $13.5 \%$ \\
Tax rates $\tau_{I}=\tau_{P}$ & $0.3 \%$ & $0.4 \%$ & $1.4 \%$ & $3.2 \%$ \\
Vacancy costs $\Phi_{V}$ & 0.42 & 0.42 & 0.24 & 0.24 \\
\hline
\end{tabular}

This table repeats the policy experiment first for alternative values of the replacement rate, the percentage of net wages which are replaced by unemployment benefits $b$. 
Table 9: Robustness to Choice of Firm Exit Rate $\delta$

\begin{tabular}{|l|cc|cc|}
\hline & $\delta=0.006$ & & $\delta=0.01$ & \\
\hline & US $\Phi_{E}$ & Euro $\Phi_{E}$ & US $_{E}$ & Euro $\Phi_{E}$ \\
\hline Unemployment $u\left(\sigma^{*}\right)$ & $5.5 \%$ & $7.5 \%$ & $5.5 \%$ & $10.3 \%$ \\
Unemployment duration $\frac{1}{\theta q(\theta)}$ & 2.2 & 3.1 & 2.2 & 4.4 \\
Vacancy duration $\frac{1}{q(\theta)}$ & 4.2 & 3.0 & 4.2 & 2.1 \\
Replacement rate & 0.30 & 0.30 & 0.30 & 0.30 \\
Matching elasticity $\eta=\beta$ & 0.50 & 0.50 & 0.50 & 0.50 \\
\hline Real unemployment benefit $b$ & 0.28 & 0.27 & 0.28 & 0.27 \\
Total separation rate $\chi$ & 0.026 & 0.026 & 0.026 & 0.026 \\
Labor market tightness $\theta\left(\sigma^{*}\right)$ & 1.89 & 0.97 & 1.89 & 0.48 \\
\hline Equ. demand elasticity $\sigma^{*}$ & 116.1 & 9.2 & 82.3 & 6.8 \\
Real net wage $\frac{w}{P}\left(1-\tau_{I}\right)$ & 0.94 & 0.90 & 0.94 & 0.88 \\
Res. Utility $r V^{U}$ & 0.90 & 0.85 & 0.90 & 0.81 \\
Worker's Match Surplus & 0.04 & 0.05 & 0.04 & 0.07 \\
Markup & $0.4 \%$ & $12.2 \%$ & $0.6 \%$ & $17.2 \%$ \\
Tax rates $\tau_{I}=\tau_{P}$ & $0.9 \%$ & $1.2 \%$ & $0.9 \%$ & $1.7 \%$ \\
Vacancy costs $\Phi_{V}$ & 0.33 & 0.33 & 0.33 & 0.33 \\
\hline
\end{tabular}

This table repeats the policy experiment first for alternative values of the monthly firm exit rate, corresponding to the upper and lower bounds of the range of 5-year exit rates found in micro-data. 
Table 10: Robustness to Choice of $\eta=\beta$

\begin{tabular}{|l|cc|cc|}
\hline & $\eta=\beta=0.40$ & & $\eta=\beta=0.72$ & \\
\hline & US $\Phi_{E}$ & Euro $\Phi_{E}$ & US $\Phi_{E}$ & Euro $\Phi_{E}$ \\
\hline Unemployment $u\left(\sigma^{*}\right)$ & $5.5 \%$ & $7.1 \%$ & $5.5 \%$ & $19.4 \%$ \\
Unemployment duration $\frac{1}{\theta q(\theta)}$ & 2.2 & 4.2 & 2.2 & 10.8 \\
Vacancy duration $\frac{1}{q(\theta)}$ & 4.2 & 3.1 & 4.2 & 0.1 \\
Replacement rate & 0.30 & 0.30 & 0.30 & 0.30 \\
Matching elasticity $\eta=\beta$ & 0.40 & 0.40 & 0.72 & 0.72 \\
\hline Real unemployment benefit $b$ & 0.28 & 0.26 & 0.29 & 0.26 \\
Total separation rate $\chi$ & 0.026 & 0.026 & 0.026 & 0.026 \\
Labor market tightness $\theta\left(\sigma^{*}\right)$ & 1.89 & 1.22 & 1.89 & 0.01 \\
\hline Equ. demand elasticity $\sigma^{*}$ & 116.6 & 8.1 & 53.6 & 5.1 \\
Real net wage $\frac{w}{P}\left(1-\tau_{I}\right)$ & 0.92 & 0.87 & 0.96 & 0.88 \\
Res. Utility $r{ }^{U}$ & 0.88 & 0.83 & 0.92 & 0.75 \\
Worker's Match Surplus & 0.04 & 0.04 & 0.04 & 0.13 \\
Markup & $0.5 \%$ & $14.1 \%$ & $0.5 \%$ & $24.4 \%$ \\
Tax rates $\tau_{I}=\tau_{P}$ & $0.9 \%$ & $1.1 \%$ & $0.9 \%$ & $3.5 \%$ \\
Vacancy costs $\Phi_{V}$ & 0.48 & 0.48 & 0.13 & 0.13 \\
\hline
\end{tabular}

This table repeats the policy experiment first for alternative values of the matching elasticity, corresponding to the lower bound of values reported by Petrongolo and Pissarides (2001) and to the relatively high value of 0.72 estimated by Shimer (2005). 


\section{Appendix D Figures}

Figure 1: Population-weighted average unemployment rates for the US/UK and continental Europe.

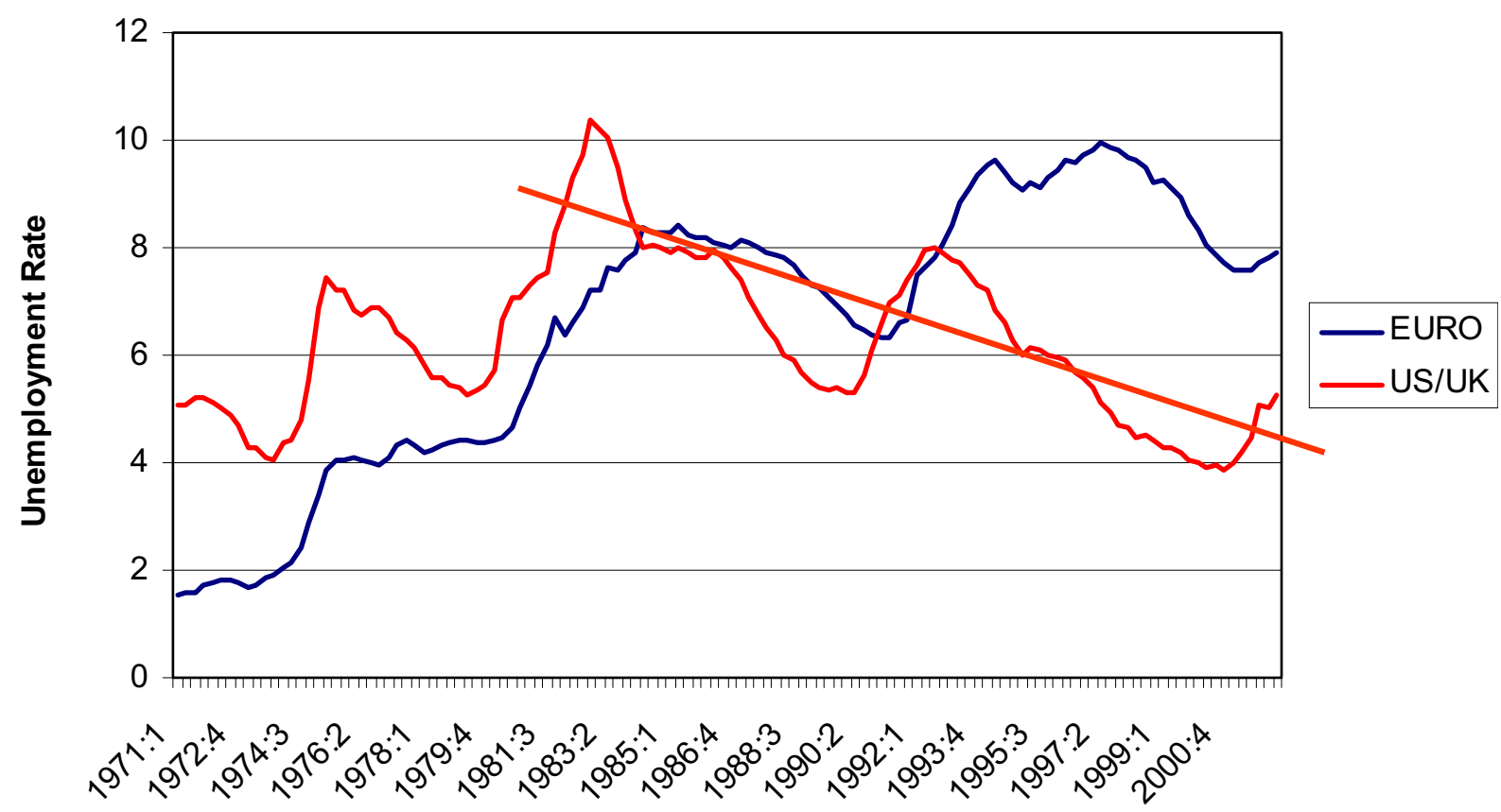


Figure 2: U.S. Union Coverage Rates.

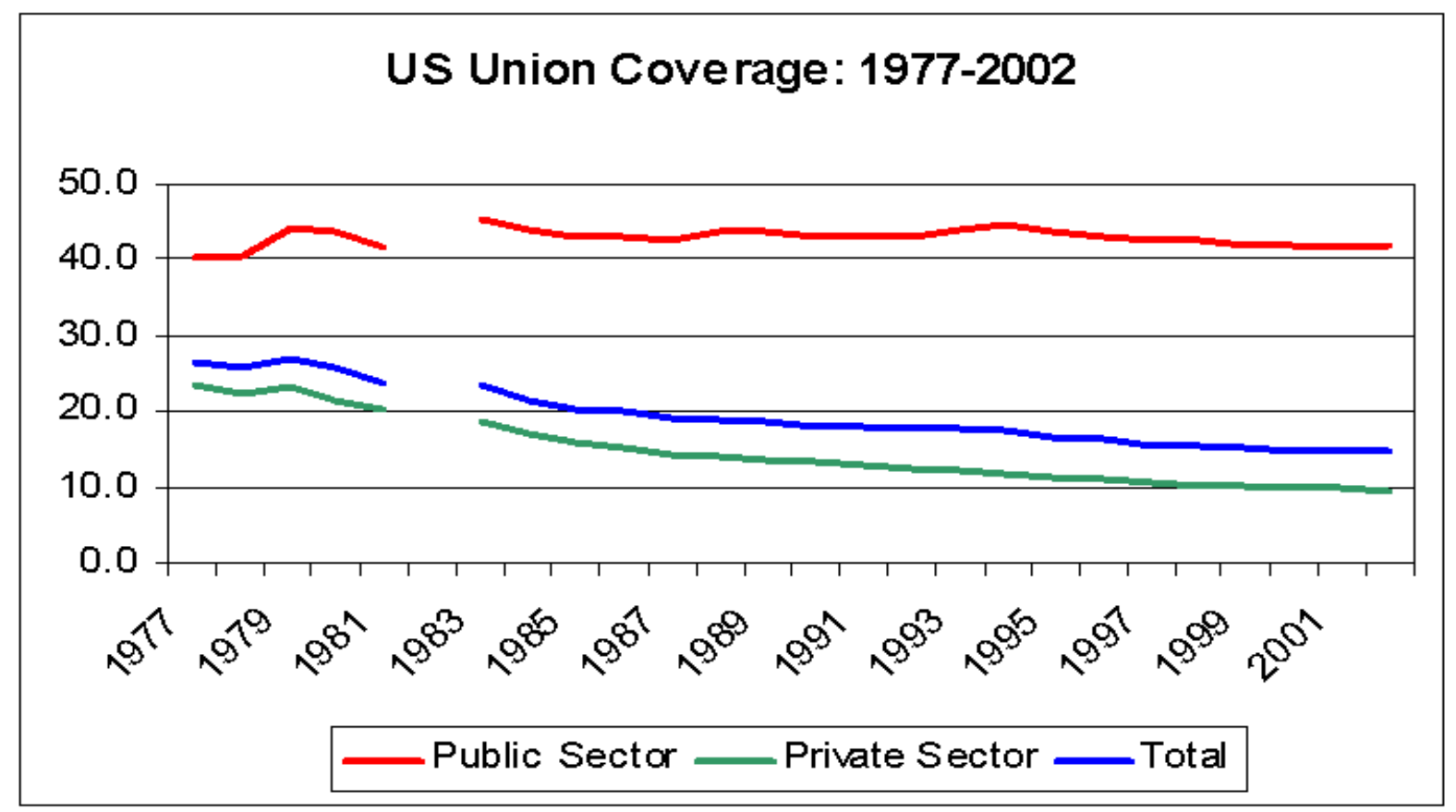

Data source: BLS data made available in time series form by Barry Hirsch and David Macpherson on their website ht t p: / / www. uni onst at s. com and documented in Hirsch and Macpherson (2003). 
Figure 3: U.S. Union Coverage Rates vs Market Share of Industries, 1992.

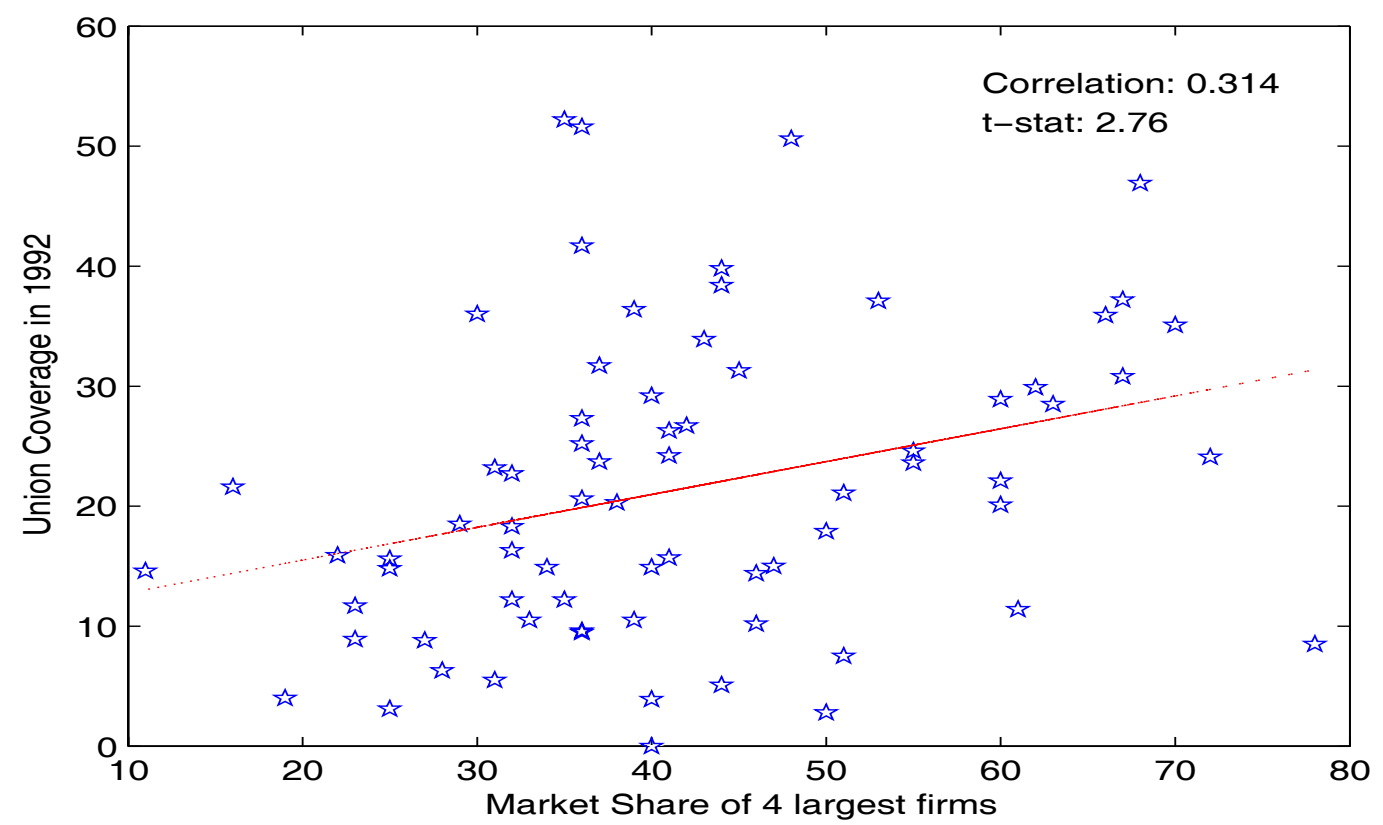

Data source: BLS data made available in time series form by Barry Hirsch and David Macpherson on their website www.unionstats.com and documented in Hirsch and Macpherson (2003), combined with information from the Census of Manufacturing. 
Figure 4: Short-Run Equilibria
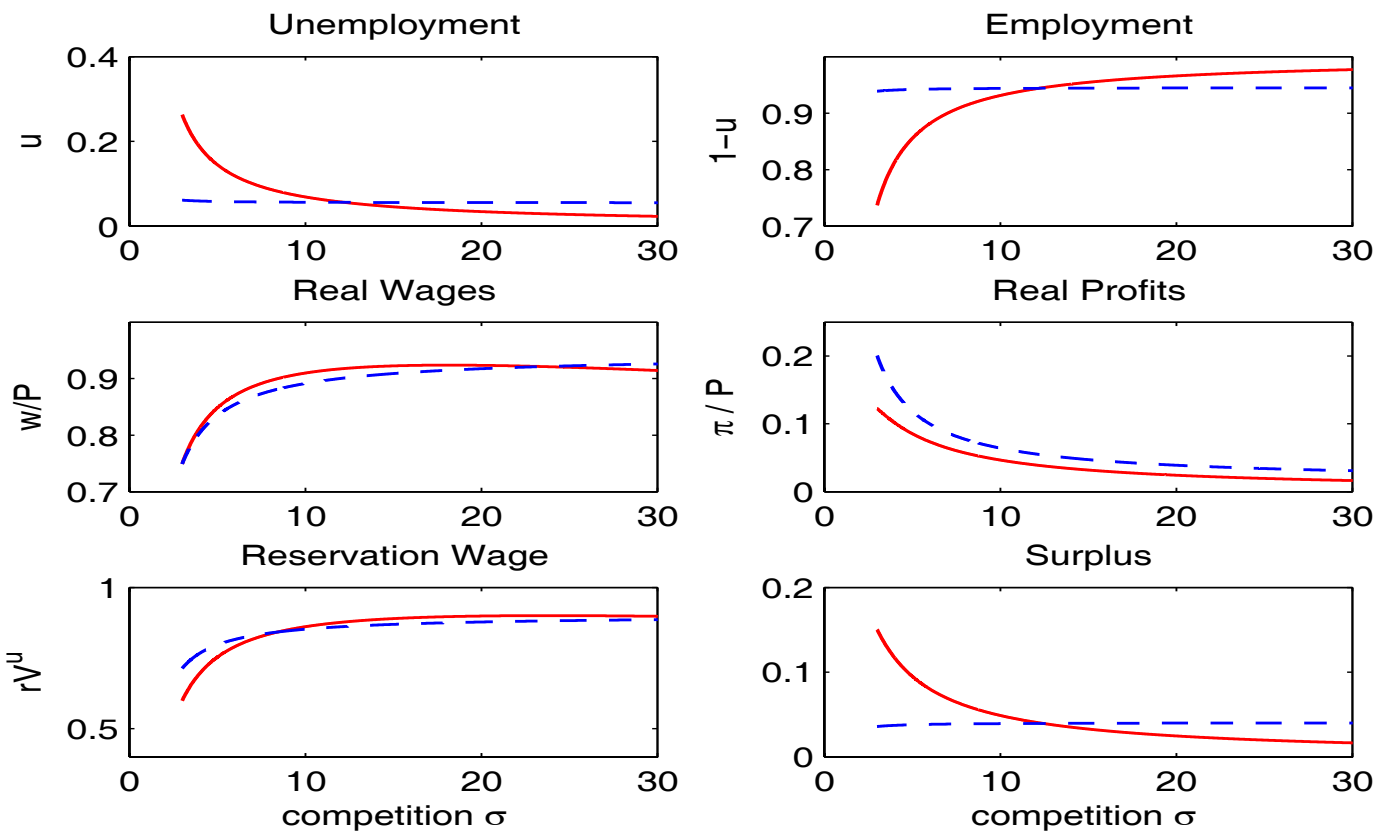
Figure 5: Determination of long-run equilibrium competition level $\sigma^{*}$ for each entry cost and bargaining regime pair.
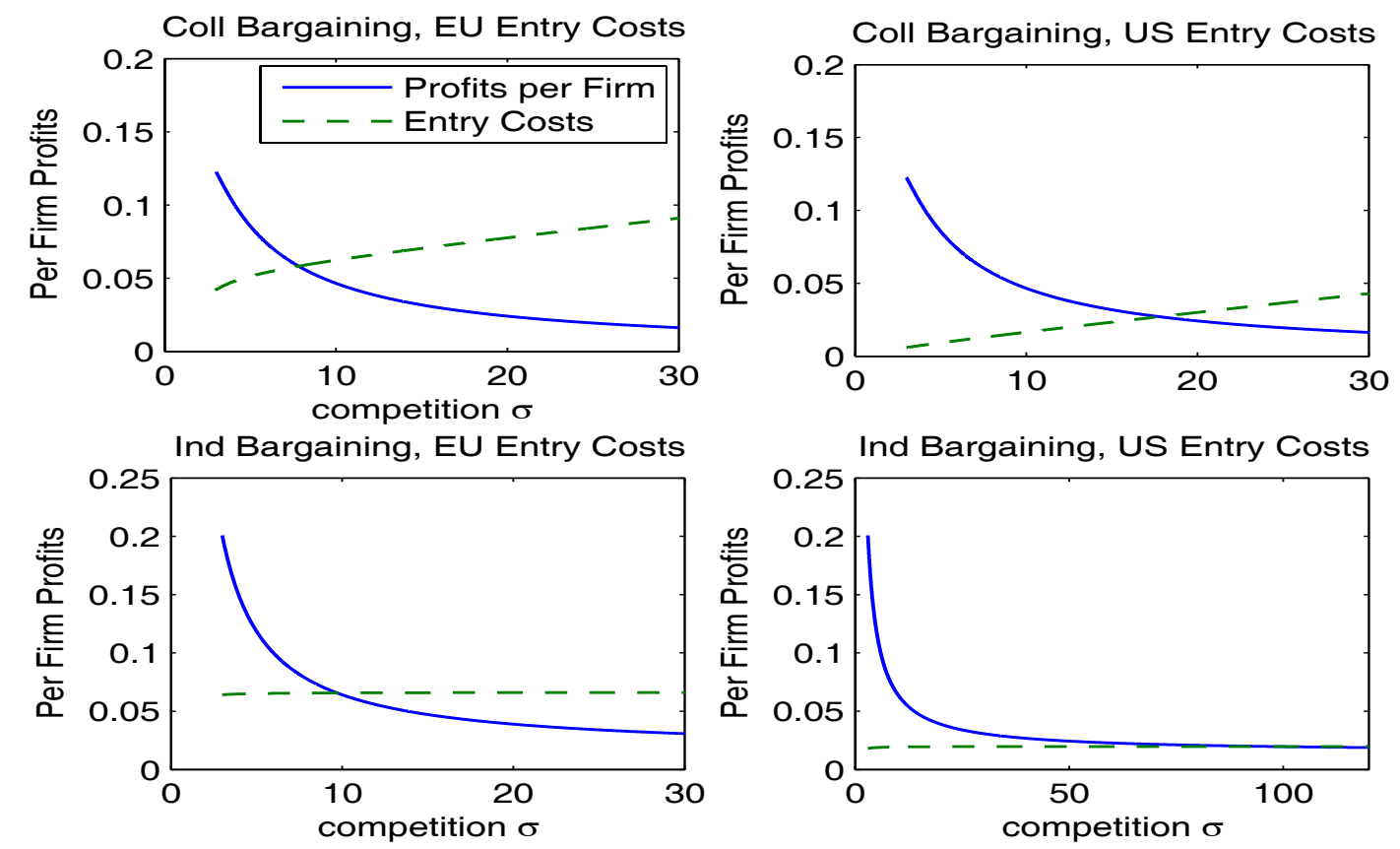
Figure 6: Endogenous bargaining institution: Conditions for symmetric Nash equilibria.
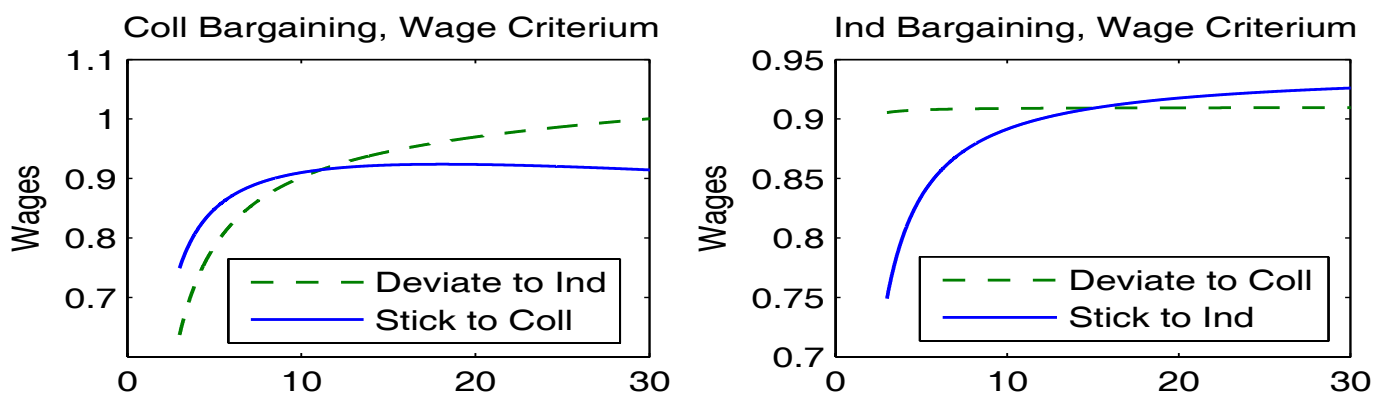

Coll Bargaining, Employment Criterium
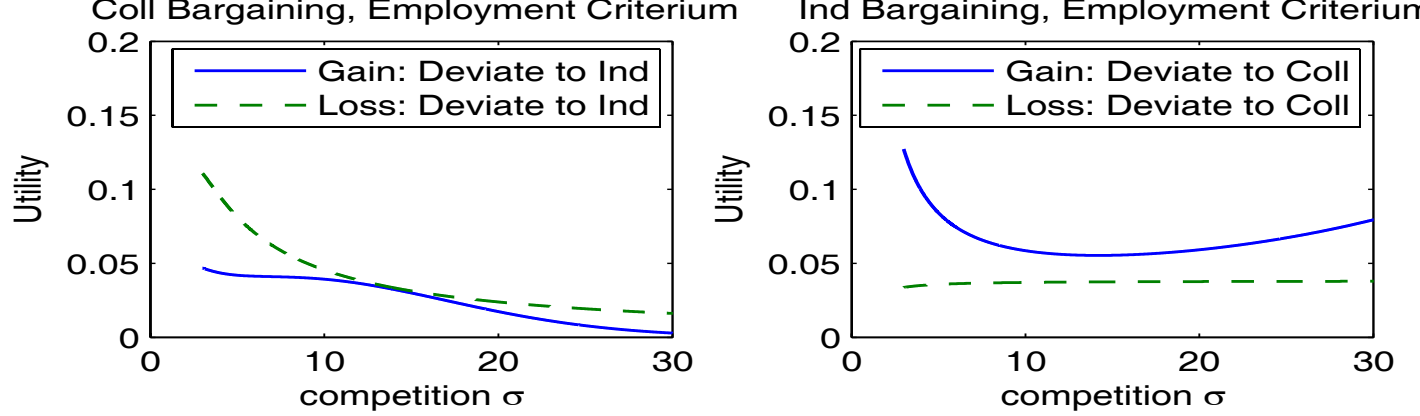